\title{
Booms and Busts with dispersed information
}

\author{
Kenza Benhima * \\ UNIVERSITY OF LAUSANNE
}

August 2013

\begin{abstract}
This paper lays down a model where dispersed information generates booms and busts in economic activity. Boom-and-bust dynamics start when firms are initially over-optimistic about demand due to an aggregate noise shock in their signals. Consequently, they over-produce, which generates a boom. This however also depresses their mark-ups, which, to firms, signals low demand and overturns their expectations, generating a bust. This emphasizes a novel role for imperfect common knowledge: dispersed information makes firms ignorant about their competitors' actions, which makes them confuse high noise-driven supply with low fundamental demand. Boom-and-bust episodes are more dramatic when the aggregate noise shocks are more unlikely and when congestion effects are stronger.
\end{abstract}

Keywords: Imperfect Common Knowledge, Expectations, Recessions.

JEL Classification Numbers: E32, D83, D52.

\section{Introduction}

Boom-and-bust episodes are a recurring feature in economic history. Boom periods where new projects attract large resources are followed by downturns where few resources are invested. Famous recent episodes include the 2001 dotcom bubble or the recent housing boom and the subsequent subprime crisis. Before that, the Dutch Tulip Mania in the 17th century and the boom in railroad construction that

${ }^{*}$ I would like to thank Daniel Andrei, Georges-Marios Angeletos, Philippe Bacchetta, Isabella Blengini, Fabrice Collard, Luisa Lambertini, Baptiste Massenot, Aude Pommeret, seminar participants at the University of Lausanne, EPFL, the University of Cergy-Pontoise, the University of Zurich and the University of Bern, and participants to the CIRPÉE-DEEP-TSE Macroeconomics Workshop in Toulouse for helpful comments. Helena Texeira provided useful research assistance for this project. 
preceded the recession of 1873 in the US are well-known historical examples. The fact that economic activity can turn from heedless optimism to dire pessimism is also a cornerstone in economic theory. Keynes (2006) argued that "animal spirits" play a fundamental role in the economy, while Pigou (1927) advanced the idea that business cycles may be the consequence of "waves of optimism and pessimism".

The objective of the paper is to show how such successions of optimism and pessimism waves may arise as the result of imperfect common knowledge. We emphasize a novel role for dispersed information. Because it makes agents ignorant about the others' actions, they are unable to distinguish demand shocks from supply shocks when analyzing their individual economic outcomes. This has the potential to overturn their initial assessment of the state of the economy, generating boom-and-bust dynamics.

In our model, busts originate in the preceding booms as the result of an initial over-optimistic signal about demand. The model focuses on the difficulties faced by firms to correctly forecast the state of demand when deciding on their supply level. First, information is dispersed, which makes firms ignorant not only about the fundamental state of the economy but also about their competitors' actions. Second, signals are endogenous, which means that firms try to infer the state of demand from their economic outcomes. When a positive aggregate noise shock occurs, i.e. when firms are on average excessively optimistic about the state of demand, they over-produce, which generates a boom. This however also depresses their profits and mark-ups, which, to firms, signals low demand. This makes their new expectations excessively pessimistic, generating a bust. Importantly, expectations do not simply reverse to the true value of demand but undershoot it. Boom-and-bust cycles arise because firms rationally confuse high supply due to a spurious aggregate signal with low fundamental demand.

Importantly, firms get endogenous information, but this endogenous information is incomplete, because it comes from their market interactions. ${ }^{1}$ In that case, market incompleteness is crucial because it shapes the information set of firms. Here we assume that the labor market opens before the goods market and that transactions take place in nominal terms. Firms then only observe the nominal wage when deciding their labor hiring (and hence their production), and observe their nominal price (and hence their mark-up) only at the end of period. As a result, quantities are contingent on firms' limited information, while mark-ups are contingent on both information and the realized state. As a consequence, firms use their mark-ups to update their information at the end of period. However, markups do not reveal the true fundamental because they are also driven by the other

\footnotetext{
${ }^{1}$ Here, precisely, we mean by endogenous information market-generated information, in the spirit of Hellwig (2006), Hellwig and Venkateswaran (2009) and Graham and Wright (2010). Information is not endogenous in the sense of Sims (2003), where agents choose their amount of attention.
} 
agents' actions, which firms do not observe as a result of dispersed information.

This approach provides several insights. First, the extent of macroeconomic congestion effects determines the severity of busts following booms, as congestion worsens the signals that result from over-production. This result is consistent with the industry evidence in Hoberg and Phillips (2010). They show that boom and bust dynamics are more likely to arise in competitive industries. Competition, satiation, fixed inputs are some realistic sources of congestion. Second, the less frequent noise shocks are, the more severe are the boom-bust cycles. This is because firms believe more easily that negative signals arise from actual low demand when noise shock are less likely. Third, we show that temporary aggregate demand shocks which firms mistakenly interpret as a permanent shock can play the role of the initial aggregate noise shock. In that case, the dynamics start with an increase in credit, which is consistent with several boom-and-bust episodes.

The model focuses on the role of firms' performances in shaping their expectations and generating downturns. This approach is supported by Figure 1 which represents firms' unit profits and mark-ups in the US, around the NBER recessions. ${ }^{2}$ The Figure also features the peaks in profits and mark-ups. It clearly appears that profits and mark-ups peaked several quarters before the onset of many recessions. In particular, the 2001 and 2008 recessions are both preceded by a gradual decrease in profits and mark-ups. Our setup is consistent with these facts as firms form their expectations based on their profits (equivalently, their markups), which contributes to turn a boom into a bust. The recession of 1990 shows the same features. The picture is less clear for the recessions of the 1970's and the 1980 's, which were induced either by the oil price or by monetary policy. The recessions of 1953, 1958 and 1960 are also preceded by a gradual decrease in profits and mark-ups. Several of these episodes were characterized by excessive optimism about demand. ${ }^{3}$ Figure 2 represents for robustness purposes the peaks in profits with the peaks in GDP. In the cases where a peak in profits preceded a recession, it also preceded the corresponding peak in GDP. The fact that it preceded the peak in expected GDP indicates that expectations are indeed a consistent channel

\footnotetext{
${ }^{2}$ We use a measure of the mark-up based on average costs proposed by Ramey and Nekarda (2010) because this is consistent with our model.

${ }^{3}$ Between 2000 and 2006, the number of vacant houses all year round rose by $20 \%$ while construction spending increased by $45 \%$, feeding the real estate bubble that lead to the subprime crisis. During the dotcom bubble, many companies such as Pets.com, Webvan and Boo.com went bankrupt because they failed to build a customer base. Similarly, the 1960 recession coincided with a drop in domestic car demand, which shifted to foreign cars; the recession of 1958 can also be explained by the reduction in foreign demand, due to a world-wide recession. A last supporting example is the recession of 1953. According to the Council of Economic Advisors (1954): "Production and sales gradually fell out of balance in the early months of 1953. [...] The reason was partly that, while demand was high, business firms had apparently expected it to be higher still."
} 
through which reversals in profits lead to reversals in economic activity.

Close to our approach, the "news" shocks literature relates optimism and pessimism waves to aggregate signals about future productivity. ${ }^{4}$ Depressions nevertheless do not breed into past exuberance. Waves of optimism fade out progressively as agents learn about the true state. They do not generate pessimism. Indeed, this literature usually focuses on the boom, not on the bust. In particular, the main challenge has been to explain how positive news about the future could generate a boom. Notable exceptions are Beaudry and Portier (2004), Christiano et al. (2008) and Lambertini et al. (2011), where busts arise when a positive news is revealed to be false, that is when agents learn the true fundamental. In our setup, on the opposite, busts arise because agents are confused by the negative signals they get. This is consistent with the idea that recessions are characterized by high uncertainty (Bloom et al., 2012).

Another difference with the news shocks literature is that our fundamental shock is a demand shock, not a productivity shock. This choice has several motivations. First, it seems that the failure of firms to properly assess demand has played a key role in some significant boom-and-bust episodes, as argued above. Second, it seems more realistic to assume that firms have troubles assessing demand rather than their own productivity. Lack of common knowledge has therefore deep foundations in the absence of communication between firms and households. Third, if managers were imperfectly able to assess their firm's productivity, boomand-bust cycles would not appear. Indeed, after an over-optimistic productivity signal, firms would still over-produce and observe lower prices than expected, but this would confirm their optimistic expectations, as low prices also signal high productivity. In that case, there is no confusion between demand and supply, because both the fundamental and the noise shock affect the supply side.

This paper relates also to imperfect information models with dispersed information, which date back to Lucas (1972) and Frydman and Phelps (1984). ${ }^{5}$ Unlike us, these models do not explain boom-and-bust cycles. This is because in the standard approach the decision variables of firms are prices, not quantities. Indeed, if firms compete on prices (Bertrand competition), firms' decisions are strategic complements, whereas if they compete on quantities (Cournot competetion), firms' decisions are strategic substitutes, as in our framework. ${ }^{6}$ This strategic substitutability is key to overturn the firms' expectations after an optimism wave, as the negative signals firms get come from congestion effects. Our approach, where firms compete on quantities, is justified by the fact that capacity

\footnotetext{
${ }^{4}$ See, among others: Beaudry and Portier (2006), Jaimovich and Rebelo (2009), Blanchard et al. (2009) and Lorenzoni (2009).

${ }^{5}$ See also Woodford (2001), Sims (2003), Lorenzoni (2009), Amador and Weill (2012) and Angeletos and La'O (2009). This literature is surveyed in Hellwig (2006) and Lorenzoni (2009).

${ }^{6}$ See Angeletos and Pavan (2007).
} 
decisions are medium-term decisions, which is the horizon at which boom-and-bust episodes arise.

Finally, we provide a simple model where imperfectly informed firms learn the state of demand from equilibrium prices. This channel, from equilibrium outcomes to information, has been less studied in the literature than the reverse channel, from information to equilibrium outcomes, due to technical difficulties. ${ }^{7}$ Closest to our approach, Hellwig and Venkateswaran (2009) and Graham and Wright (2010) present business cycle models where agents learn from their market interactions. However, in Hellwig and Venkateswaran (2009), the focus is on the price-setting behavior of firms and, contrary to our paper, firms compete on prices, not on quantities. Graham and Wright (2010) focus on the role of market incompleteness in generating heterogeneous information. While in their model, market incompleteness lies in a segmented labor market, in our model, it is due to the fact that transactions take place exclusively in monetary terms. Finally, Gaballo (2013) shows, in a model similar to ours, that dispersed-information equilibria can be sustained even in the absence of idiosyncratic disturbances.

Section 2 presents the set up, a standard Dixit-Stiglitz model with imperfect competition, and Section 3 defines the equilibrium. To convey the intuition of the mechanism, we first present a version of the model in Section 4 where transactions take place in labor terms. As a result, the wage, which is normalized to one, does not convey any information at all. The model is then simpler to solve but the fundamental mechanism is present. Section 5 then presents the full monetary version, where the nominal wage gives additional but partial information about the fundamental. In this section, we also examine the link between boom and bust events and credit. Section 6 concludes.

\section{Set up}

We consider a two-period general equilibrium model with imperfect competition à la Dixit-Stiglitz. There is one representative household who consumes a continuum of differentiated goods indexed by $i \in[0,1]$ and supplies labor on a competitive market. Each good is produced by a monopolistic firm using labor. Aggregate demand is affected by a preference shock.

\footnotetext{
${ }^{7}$ Townsend (1983) and Sargent (1991) are early attempts. More recently, Rondina and Walker (2012) and Nimark (2011) provide new techniques to study equilibria in which agents with heterogeneous information solve signal extraction problems and in which prices and quantities endogenously reveal information. Other contributions, such as Angeletos et al. (2010), examine the interactions between real variables and asset prices in a dispersed information context.
} 


\subsection{Preferences and technology}

There is a representative household with the following utility function:

$$
U=U_{1}+\beta U_{2}
$$

where $0<\beta<1$ is the discount factor and $U_{t}$ is period- $t$ utility:

$$
U_{t}=\Psi \frac{Q_{t}^{1-\gamma}}{1-\gamma}-\frac{L_{t}^{1+\eta}}{(1+\eta)}
$$

$Q=\left(\int_{0}^{1}\left(Q_{i}\right)^{1-\rho} d i\right)^{\frac{1}{1-\rho}}$ is the consumption basket composed of the differentiated goods $Q_{i}, i \in[0,1]$, and $L$ is labor. $\rho \in(0,1)$ is the inverse of the elasticity of substitution between goods. $\gamma>0$ is the inverse of the elasticity of intertemporal substitution. $\eta>0$ is the inverse of the Frisch elasticity of labor supply. $\Psi$ determines the preference of the household for consumption relative to leisure.

Money is the numéraire. The consumer maximizes his utility under the following budget constraint, expressed in nominal terms:

$$
\int_{0}^{1} P_{i t} Q_{i t} d i+M_{t}+B_{t}=W_{t} L_{t}+\int_{0}^{1} \Pi_{i t} d i+M_{t-1}+r_{t-1} B_{t-1}+T_{t}
$$

where $P_{i t}$ is the nominal price of good $i, T_{t}$ are the nominal transfers from the government, $M_{t}$ are money holdings, $B_{t}$ are bond holdings, $r_{t-1}$ is the return on bond holdings, $W_{t} L_{t}$ is the nominal labor income and $\Pi_{i t}$ are the nominal profits distributed to the household by firm $i$.

Money is created by the government and supplied to households through transfers $T$, following $M_{t}-M_{t-1}=T_{t}$. Bonds are in zero supply, so $B_{t}=0$ in equilibrium. The only role played by bonds in this economy is to make money a dominated asset.

Finally, the household faces a cash-in-advance constraint, $\int_{0}^{1} P_{i t} Q_{i t} d i \leq M_{t-1}+$ $T_{t}$. Because money yields no interest, this constraint holds with equality. Solving for the price index and combining with the government budget constraint, we obtain:

$$
P_{t} Q_{t}=M_{t}
$$

where $P=\left(\int_{0}^{1}\left(P_{i}\right)^{\frac{-(1-\rho)}{\rho}} d i\right)^{\frac{-\rho}{1-\rho}}$ is the general price index.

There is a $[0,1]$ continuum of firms who produce differentiated goods. The production function of each firm $i \in[0,1]$ involves labor with a constant return to scale technology:

$$
Q_{i t}=L_{i t}
$$


Firm $i$ 's profits are therefore:

$$
\Pi_{i t}=P_{i t} Q_{i t}-W_{t} Q_{i t}
$$

Firm $i$ 's unit profit is therefore $P_{i t}-W_{t}$ and its mark-up is $P_{i t} / W_{t}$.

\subsection{Shocks, timing and information}

At the beginning of period 1, the economy is hit by a shock on the preference parameter $\Psi$. This represents a permanent "demand shock" for intermediate goods. ${ }^{8}$ We assume that $\psi=\log (\Psi)$ follows a normal distribution with mean zero and standard error $\sigma_{\psi}$. We assume that $\psi$ is directly observed by households, but not by firms. This assumption simply means that households do not directly communicate their preferences to firms. The dynamics of the model is determined by the inability of firms to correctly forecast $\psi$.

The money supply is set by the government to $M_{t}=\bar{M} \exp \left(m_{t}\right)$, where $m_{t}$ is a monetary shock. $m_{t}$ follows a normal distribution with mean zero and standard error $\sigma_{m}$. Because the household is involved in the market for money, she observes $m_{t}$ directly but the firm does not. Monetary shocks do not play a fundamental role in the model. They merely contribute to make nominal variables imperfect signals of the fundamental shock $\psi{ }^{9}$

At this stage, we can define $\Omega_{i t}$, the set of information available to firm $i$ when making its time-t production decision. At the beginning of period 1 , firm $i$ receives an exogenous signal about $\psi$ that incorporates both an aggregate and an idiosyncratic error:

$$
\psi_{i}=\psi+\theta+\lambda_{i}
$$

where $\theta$ and $\lambda_{i}$ are both normal with mean zero and respective standard errors $\sigma_{\theta}$ and $\sigma_{\lambda} . \theta$ is an aggregate noise shock, while $\lambda_{i}$ is an idiosyncratic noise shock that cancel out at the aggregate level: $\int_{0}^{1} \lambda^{i} d i=0$. In section 5 , we lay down an extension of the model where this initial signal is endogenous and $\theta$ and $\lambda_{i}$ are temporary demand shocks. We assume that, besides $\psi$ and $m_{t}$, the household observes $\theta$ and $\lambda_{i}{ }^{10}$

The other signals observed by firms when making their production decisions

\footnotetext{
${ }^{8}$ It can also be modelled as a productivity shock in the final good production. Variations in the demand for intermediate goods can then arise both from a preference shock or a technology shock.

${ }^{9}$ We do not introduce shocks on productivity in the model, as productivity is observed by firms in any case, and our focus is on firms' imperfect information, not households'. In this context, the problem of firms is to infer the shocks that they cannot observe.

${ }^{10}$ This is without loss of generality given that the household observes all quantities and prices in all markets, and therefore can infer $\theta$ and $\lambda_{i}$ using her information on $\psi$ and $m_{t}$.
} 
depend on the market assumptions. We consider an environment where prices are fully flexible, but where markets are incomplete. First, each period, the labor market opens before the goods market. Second, transactions are made in terms of money and wages are not contingent. As a result, labor hirings and nominal wages are determined first, before firms can observe nominal prices. This has two important consequences. On the one hand, it makes quantities predetermined with regards to nominal prices. In other words, quantities are contingent on the exogenous signal $\psi_{i}$ and on the nominal wage $W_{t}$, but not on the relevant variable for their output decisions, which is the mark-up $P_{i t} / W_{t}$. On the other hand, nominal prices incorporate new information that the firms can use when setting their next period supply.

Therefore, the information set of firm $i$ at the beginning of period 1 is $\Omega_{i 1}=$ $\left\{\psi_{i}, W_{1}\right\}$. At the beginning of period 2 , firms have observed the price of their good during period 1 , so $\Omega_{i 2}=\left\{\psi_{i}, P_{i 1}, W_{1}, W_{2}\right\}$.

Importantly, we assume that the aggregate supply is not part of their information set. The idea behind this restrictive information structure is that firms pay attention to their local interactions and limited attention to public releases of aggregate information. Firms do collect public information (the nominal wage for example), but only if they are confronted to this information during their economic interactions. Aggregate supply is not part of their information set because they trade an individual good. ${ }^{11}$

In order to save notations, we denote by $E_{i t}(y)$ the expected value of variable $y$ conditional on $\Omega_{t}^{i}$.

\section{Equilibrium}

An equilibrium is a sequence of nominal prices, nominal wages, money holdings, production levels, labor supplies such that, in each period $t=1,2$ : (i) the household maximizes his utility (1) subject to his budget constraint (3) and the cash-in-advance constraint, given full information about the shocks hitting the economy and given the nominal prices and wages; (ii) each firm $i$ sets its supply $Q_{i t}$ monopolistically to maximize its profits given its information set $\Omega_{i t}$; (iii) the money market, labor market and the intermediate good markets clear.

\footnotetext{
${ }^{11}$ We could add noisy aggregate quantities to the information sets to represent imperfect attention to aggregate supply, but we prefer to represent imperfect information in a parsimonious way by assuming that agents simply do not observe aggregate quantities.
} 


\subsection{Household's decisions}

The consumer's maximization program yields the following demand for each variety:

$$
Q_{i t}=Q_{t}\left(\frac{P_{i t}}{P_{t}}\right)^{\frac{-1}{\rho}}
$$

This equation simply states that the demand for good $i$ is increasing in total demand and decreasing in the relative price of good $i$.

In logarithmic terms, this equation writes:

$$
p_{i}-p=\rho\left[q-q_{i}\right]
$$

where lower-case letters denote the log value of the variable and where time subscripts are dropped. Everything else equal, aggregate income increases the demand for good $i$, which increases $p_{i}$, and the more so as the elasticity of substitution between goods $1 / \rho$ is low ( $\rho$ is large).

The consumer's maximization program yields the following demand for goods:

$$
Q^{\gamma} L^{\eta}=\frac{\Psi W}{P}
$$

This equation represents the trade-off between leisure and consumption. When the demand shock $\psi$ is high, agents prefer consumption over leisure and therefore they work and consume more. Similarly, when the real wage $W / P$ is high, leisure is relatively less costly, which stimulates aggregate demand $Q$.

In logs, and after using $Q=L$, this yields:

$$
w-p=\sigma q-\psi
$$

where $\sigma=\gamma+\eta \cdot 1 / \sigma$ is the macro elasticity of labor supply to the real wage. When $\sigma$ is high, this elasticity is low and the wage reacts strongly to changes in supply $q . \sigma$ can then be seen as the parameter that governs of real rigidities in the economy, or aggregate congestion, since aggregate supply increases costs through that channel.

The money market clears, so $P_{t} Q_{t}=\bar{M} \exp \left(m_{t}\right)$. In logs, this gives:

$$
p+q=m
$$

The constant term is neglected for simplicity. 


\subsection{Optimal supply by firms}

Optimal supply by firm $i$ must be such that prices satisfy:

$$
E_{i}\left(\frac{P_{i t}}{W_{t}}\right)=\frac{1}{(1-\rho)}
$$

This simply means that the mark-up $P_{i t} / W_{t}$ must be equal to $1 /(1-\rho)$ in expectations. Since shocks are log-normal, this equation can be written in logs:

$$
E_{i}\left(p_{i}\right)-w=0
$$

where the constant term has been discarded. It is useful to define the normalized supply $\hat{q}_{i}=\sigma q_{i}$. By using the individual and aggregate demand equations (7) and (8), the optimal - normalized - individual supply can be written as a function of expected aggregate supply and the expected fundamental shock:

$$
\hat{q}_{i}=\tilde{\sigma} E_{i}(\psi)-(\tilde{\sigma}-1) E_{i}(\hat{q})
$$

where $\tilde{\sigma}=\sigma / \rho$. In order to decide its optimal supply $\hat{q}_{i}$, firm $i$ has two variables to infer: the fundamental shock $\psi$, but also the aggregate supply $\hat{q}$. Indeed, firms exert an externality on each other due to congestion and income effects. Aggregate supply has two opposite effects on individual profits. First, it increases the real wage $w-p$, and the more so as $\sigma$ is large, that is as the macro elasticity of labor supply is low (congestion effect). Second, it increases the real price $p_{i}-p$ of good $i$, but the less so as the elasticity of substitution $1 / \rho$ is large (income effect). Therefore, profits are adversely affected by aggregate supply when both $\sigma$ and $1 / \rho$ are large. For $\tilde{\sigma}<1$, the positive income effect counteracts the negative congestion effect and quantity-setting features strategic substitutabilities. For $\tilde{\sigma}>1$, the negative congestion effect counteracts the positive income effect and quantitysetting features strategic complementarities.

In the remainder of the paper, we make the following assumption:

Assumption 1 (Congestion) $\tilde{\sigma}>1$.

This assumption states that the congestion effect dominates the income effect. As we will see later, this assumption is strongly supported by the data.

\subsection{Perfect information / perfect markets outcome}

Before solving the model with imperfect information, consider the perfect information outcome. If firms were all able to observe $\psi$ directly, then they would 
set:

$$
\hat{q}_{i t}=\hat{q}_{t}=\psi
$$

and the equilibrium mark-up would satisfy:

$$
p_{i t}-w_{t}=0
$$

Note that this perfect information outcome would also arise if markets were complete, that is if firms were able to specify wages in terms of their individual good. Indeed, the wage in terms of good $i w-p_{i}$ is equal to minus the mark-up $p_{i}-w$. Hence, for firm $i$ it is equivalent to set the wage in terms of good $i$ and the mark-up. The firm can therefore satisfy its optimality condition $p_{i}-w=0$, and therefore $\hat{q}_{i}=\psi$. In practice, firms adjust their labor demand until the real wage corresponds to the desired mark-up. In the model, prices reveal the relevant information to firms only partially because markets are incomplete, as wages are specified in nominal terms.

\section{Simple version}

Before solving the full-fledged monetary model, we consider a simplified version in order to grasp the intuition. In particular, the main mechanism comes from the fact that the firm cannot observe the mark-up $p_{i}-w$, which is the relevant price for deciding its production level. It observes it partly through the nominal wage $w$, but the nominal wage is itself affected by nominal shocks, so it is only a noisy signal of the mark-up.

In this section, we consider a version of the model where transactions are specified in terms of labor, not of money. The labor market thus does not convey any information to firms, since the wage is equal to one. This has implications on the information set of firms since firms do not even observe $w$, the wage in terms of money. In this case, we have a simpler problem where the wage does not convey any information but where quantities are still determined ahead of the mark-up, which is at the core of the model's mechanism. Now quantity setting must satisfy $E_{i}\left(p_{i}-w\right)=0$ and Equation (10) is still valid. The only difference with the full monetary model is that the information sets are now $\Omega_{i 1}=\left\{\psi_{i}\right\}$ and $\Omega_{i 2}=\left\{\psi_{i}, p_{i 1}-w_{1}\right\}$.

\subsection{First period production}

Here we show that in the first period, firms' aggregate supply under-reacts to the fundamental demand shock and over-reacts to the aggregate noise shock. As a 
result, firm's mark-up, which is observed by firms at the end of period, is positively affected by the fundamental shock and negatively by the noise shock.

Indeed, as firms receive signal $\psi_{i}=\psi+\theta+\lambda_{i}$ at the beginning of period 1 , they extract information from this signal according to the following standard formula:

Lemma 1 (Period-1 forecasts) At the beginning of period 1, firm i's forecast of $\psi$ is the following:

$$
E_{i 1}(\psi)=k_{\psi} \psi_{i}=k_{\psi}\left(\psi+\theta+\lambda_{i}\right)
$$

where $k_{\psi}$ is the standard bayesian weight $k_{\psi}=\sigma_{\psi}^{2} /\left(\sigma_{\psi}^{2}+\sigma_{\theta}^{2}+\sigma_{\lambda}^{2}\right)$.

Signal $\psi_{i}$ is imperfectly correlated with $\psi$. The best forecast for $\psi$ is therefore proportional to the signal, and the elasticity of the forecast to the signal depends on the fraction of the signal volatility that is explained by the fundamental shock.

On the other hand, firm $i$ 's supply follows the optimal supply (10). In order to derive supply as a function of the shocks, we use the method of undetermined coefficients. We establish the following Proposition (see proof in the Appendix):

Proposition 1 (Period-1 production) In period 1, the supply by firm $i$ obeys to:

$$
\hat{q}_{i 1}=K_{\psi} \psi_{i}
$$

where $0<K_{\psi}<1$, and, under Assumption 1, $K_{\psi}>k_{\psi}$. At the aggregate level, firms produce the following quantities:

$$
\hat{q}_{1}=K_{\psi}(\psi+\theta)
$$

Since $K_{\psi}<1$, the aggregate supply under imperfect information, as compared with the equilibrium supply under perfect information (11), reacts less to the fundamental shock $\psi$, because information is noisy. On the opposite, aggregate supply over-reacts to the aggregate noise shock $\theta$, because firms cannot distinguish it from the fundamental.

Moreover, as there are congestion effects in the economy, we have $K_{\psi}>k_{\psi}$, which means that agents over-react to their private signal $\psi_{i}$. Each firm $i$ expects that the other firms combine their private signal with zero, the unconditional expectation of $\psi$, which is public information, to set their individual supply. Since there is strategic substitutability under Assumption 1, firms under-react to any public information, because public information is common to all firms and thus generates congestion. A contrario, firms over-react to any private information because private information is exempt from congestion effects. A positive noise shock $\theta$ therefore generates a boom that is due both to imperfect information per se but also to the over-reaction to private signals. This feature is in line with the 
literature on imperfect common knowledge and is not specific to our paper (see for example Angeletos and Pavan (2007)). Here, as we will show soon, imperfect common knowledge plays an additional role, which is to produce confusion between demand and supply. This effect plays through the new signal gathered by firms at the end of period 1, their mark-up.

\subsection{New signal}

The new signal received by firms is their mark-up:

$$
p_{i 1}-w_{1}=\psi-\frac{\tilde{\sigma}-1}{\tilde{\sigma}} \hat{q}_{1}-\frac{1}{\tilde{\sigma}} \hat{q}_{i 1}
$$

This equation comes from the combination of individual demand (7) and aggregate demand (8). The mark-up is affected directly by the fundamental shock $\psi$ since a demand shock lowers the real wage. It is also affected by the individual and aggregate supply $\hat{q}_{i 1}$ and $\hat{q}_{1}$. The individual supply decreases the mark-up because it decreases the relative price of good $i$. Importantly, aggregate supply has a negative effect on the mark-up under Assumption 1.

The firm can use $p_{i 1}-w_{1}$ to extract information on $\psi$ by combining it with its other signal $\psi_{i}$. The firm knows individual supply $\hat{q}_{i 1}=K_{\psi} \psi_{i}$, but ignores $\hat{q}_{1}$ because of dispersed information. Therefore, it can "filter" the mark-up from the influence of $\hat{q}_{i 1}$ but not from the influence of $\hat{q}_{1}$. The "filtered" mark-up writes as follows:

$$
p_{i 1}-w_{1}+\frac{1}{\tilde{\sigma}} \hat{q}_{i 1}=\psi-\frac{\tilde{\sigma}-1}{\tilde{\sigma}} q_{1}=\left(1-\frac{\tilde{\sigma}-1}{\tilde{\sigma}} K_{\psi}\right) \psi-\frac{\tilde{\sigma}-1}{\tilde{\sigma}} K_{\psi} \theta
$$

Note that the fundamental shock $\psi$ has a positive effect on the filtered markup. Indeed, as $K_{\psi}<1$, aggregate supply does not fully respond to the demand shock, so aggregate demand is in excess of supply, which stimulates the mark-up. On the opposite, the noise shock $\theta$ has a negative effect on the filtered mark-up under Assumption 1. In this case, aggregate supply is in excess of demand, which depresses the mark-up. Assumption 1 ensures that supply does not generate its own demand through the income effect. Therefore, as a result of congestion effects, a positive shock on $\theta$ makes the filtered mark-up a negative signal of $\psi$.

Dispersed information is also crucial. If firms received the same information, then they would be able to infer $q_{1}$ even without observing it directly, because they would be able to infer what the others do. They could then clean their mark-up from the influence of others' supply and infer $\psi$. Formally, if information was common $\left(\lambda_{i}=0\right)$, it would be straightforward to infer $\psi$ by combining $p_{i 1}-w_{1}$ and $\hat{q}_{1}=K_{\psi} \psi_{i}$. Of course this result is trivial since there are as many shocks 
to identify $(\psi$ and $\theta)$ as signals $\left(p_{i 1}-w_{1}\right.$ and $\left.\psi_{i}\right)$. However, even if $p_{i 1}-w_{1}$ was observed with noise, $\theta$ would not affect the filtered signal negatively. ${ }^{12}$ In short, even if firms observed low mark-ups following a positive noise shock $\theta>0$, they would be able to put these mark-ups in perspective with the high aggregate supply $\hat{q}_{1}$. As a result, low mark-ups would not be perceived as a negative signal on $\psi$, but simply as the result of high supply.

This yields the following corollary:

Corollary 1 The information available at the beginning of period 2 is summarized by two independent signals of $\psi$, a public signal $s$ and a private signal $x_{i}$, defined as follows:

$$
\begin{gathered}
s=\psi-\omega_{\theta} \theta \\
x_{i}=\psi+\omega_{\lambda} \lambda_{i}
\end{gathered}
$$

with $\omega_{\theta}=(\tilde{\sigma}-1) K_{\psi} /\left[\tilde{\sigma}-(\tilde{\sigma}-1) K_{\psi}\right]$ and $\omega_{\lambda}=\omega_{\theta} /\left(1+\omega_{\theta}\right)$. Under Assumption 1, $\omega_{\theta}>0$. Besides, $\omega_{\theta}$ is increasing in $\tilde{\sigma}$.

Proof. $s$ is obtained simply by normalizing the filtered mark-up. $x_{i}$ is obtained by combining $s$ with $\psi_{i}$. As $x_{i}$ and $s$ are independent linear combinations of $\psi_{i}$ and $p_{1 i}-w_{1}$, the information set $\left\{x_{i}, s\right\}$ is equivalent to $\left\{\psi_{i}, p_{1 i}-w_{1}\right\}$.

As suggested, Assumption 1 implies that $\theta$ generates a negative signal on $\psi$, as $\omega_{\theta}>0$. Since congestion makes the mark-up react more negatively to aggregate supply, $s$ reacts more negatively to $\theta$ when $\tilde{\sigma}$ is higher.

\subsection{Second period}

Here we show that, while the forecast $E_{i 2}(\psi)$ and the supply $\hat{q}_{i 2}$ get closer to the perfect information benchmark after a fundamental shock, they are reversed after an aggregate noise shock.

As firms receive two independent signals of $\psi$, solving for $E_{i 2}(\psi)$ is straightforward (see proof in the Appendix):

Lemma 2 (Period-2 forecasts) At the beginning of period 2, firm $i$ 's forecast of $\psi$ is the following:

$$
E_{i 2}(\psi)=f_{x} x_{i}+f_{s} s=\left(f_{x}+f_{s}\right) \psi-f_{s} \omega_{\theta} \theta+f_{x} \omega_{\lambda} \lambda_{i}
$$

with $0<f_{x}<1,0<f_{s}<1$ and $k_{\psi}<f_{x}+f_{s}<1$. $f_{s}$ is decreasing in $\tilde{\sigma}$.

\footnotetext{
${ }^{12}$ For example, suppose that firms observe $p_{i 1}-w_{1}+z$, where $z$ follows a normal distribution with mean zero and standard error $\sigma_{z}$. Firms can still use $\hat{q}_{1}$ to clean the mark-up from $\theta$ : $p_{i 1}-w_{1}+\frac{1}{\tilde{\sigma}} \hat{q}_{1}+\frac{\tilde{\sigma}-1}{\tilde{\sigma}} \hat{q}_{1}=\psi+z$.
} 
As $f_{x}+f_{s}>k_{\psi}$, following a fundamental shock $\psi$, the forecast of $\psi$ becomes closer to the fundamental in the second period as firms gather more information. On the opposite, the effect of a noise shock $\theta$ on the forecast of $\psi$ turns from positive in the first period $\left(k_{\psi}>0\right)$ to negative in the second period $\left(-f_{s} \omega_{\theta}<0\right)$. In other words, following a positive $\theta$ shock, firms observe lower mark-ups than expected, because of an excessive aggregate supply. They revise their forecasts of $\psi$ downwards, because low mark-ups can also signal a low $\psi$, that is low demand. Lemma 2 implies that this updating overturns the initial positive forecast.

Whereas the effect of $\theta$ on the second-period forecast is clearly negative when $\tilde{\sigma}>1$, the marginal impact of the congestion parameter $\tilde{\sigma}$ is not straightforward. While $\tilde{\sigma}$ has a positive effect on the reaction of the filtered mark-up $s$ to noise $\omega_{\theta}$, it has a negative impact on the weight firms put on this public signal $f_{s}$. Indeed, as the public signal becomes more reactive to $\theta$, it becomes a poorer signal of $\psi$, so firms rely less on it to infer $\psi$. However, in the limit case where $\sigma_{\theta}^{2}$ goes to zero, the first effect dominates, as suggested by the following corollary (see proof in the Appendix):

Corollary 2 As $\sigma_{\theta}^{2}$ goes to zero, $-f_{s} \omega_{\theta}$ goes to $-(\tilde{\sigma}-1) \sigma_{\psi}^{2} /\left(\sigma_{\psi}^{2}+\sigma_{\lambda}^{2}\right)$.

This implies that, following a noise-driven boom, expectations can be arbitrarily low as aggregate noise shocks are unlikely and congestion effects are strong ( $\tilde{\sigma}$ is large). Indeed, when the noise shock is unlikely, firms put a large weight $f_{s}$ on the public signal $s$, so the effect of $\tilde{\sigma}$ on $\omega_{\theta}$ dominates.

In period 2, as in period 1, the supply by firm $i$ follows Equation (10). In order to determine the optimal supply by a firm, we use the method of undetermined coefficients again and derive the following proposition (see proof in the Appendix):

Proposition 2 (Period-2 production) In period 2, optimal supply by firm $i$ obeys to:

$$
\hat{q}_{i 2}=F_{x} x_{i}+F_{s} s
$$

with $0<F_{x}<1,0<F_{s}<1$ and $K_{\psi}<F_{x}+F_{s}<1$. Under Assumption 1, we also have $F_{x}>f_{x}$ and $F_{s}<f_{s}$. At the aggregate level, firms produce the following quantities:

$$
\hat{q}_{2}=\left[F_{x}+F_{s}\right] \psi-F_{s} \omega_{\theta} \theta
$$

In period 2 , as $F_{x}+F_{s}>K_{\psi}$, following a fundamental shock $\psi$, output gets closer to its first-best value. On the opposite, the effect of the aggregate noise shock $\theta$ on aggregate supply becomes negative through the public signal $s$. A positive noise shock generates a bust in period 2 precisely because it generates a boom in period 1. Indeed, as explained above, excessive supply in period 1 depresses period 1 mark-ups, which firms rationally interpret as weak demand because they cannot exclude the possibility that low mark-ups arise from a low $\psi$. 
As in period 1, firms over-react to their private signal (here $x_{i}$ ) and under-react to their public signal (here $s$ ), as the economy features congestion effects. Whereas this property magnifies the initial boom, it mitigates the subsequent bust. This, however, is not a crucial feature of our model. It hinges on the assumption that the mark-up is not affected by any additional noise, due for example to a temporary aggregate or idiosyncratic demand shock. In the case of idiosyncratic noise, the bust could be magnified. This nevertheless does not change the main result of the model, which is the succession of booms and busts.

As for the effect of congestion on the forecast, the effect of congestion on the dynamics is ambiguous. In the case where $\sigma_{\theta}^{2}$ goes to zero, we can nevertheless derive some results, summarized by the following corollary (see proof in the Appendix):

Corollary 3 As $\sigma_{\theta}^{2}$ goes to zero, $F_{s}$ goes to $f_{s}$, so $-F_{s} \omega_{\theta}$ goes to $-(\tilde{\sigma}-1) \sigma_{\psi}^{2} /\left(\sigma_{\psi}^{2}+\right.$ $\left.\sigma_{\lambda}^{2}\right)$

As $\sigma_{\theta}^{2}$ goes to zero, the extent of imperfect information becomes smaller, and the strategic component of optimal supply disappears, which implies that $F_{s}$ goes to $f_{s}$. The optimal supply becomes closer to its certainty-equivalent counterpart where the public noise is not under-weighted, that is $\hat{q}_{i 2}=E_{i 2}(\psi)$. Applying Corollary 2, we obtain that the response of aggregate quantities to the aggregate noise shock can become arbitrarily large as congestion effects $\tilde{\sigma}$ increase.

\subsection{Numerical example}

We implement a numerical example, where the parameters are set as described in Table 1. The preference parameters $\gamma, \eta$ and $\rho$, which determine whether Assumption 1 is satisfied or not, are crucial. First, micro studies report values for the elasticity of substitution between goods that are of the order of 6-7, so we set $1 / \rho$ to $7 .{ }^{13}$ Second, $\gamma$, the inverse of the elasticity of intertemporal substitution, is admitted to be around 1 , so we set $\gamma=1{ }^{14}$ Finally, Mulligan (1999) suggests that labor supply elasticities can easily be as large as 2, which suggests a value of $1 / 2$ for $\eta$. We set $\eta$ to zero as a conservative benchmark. As a result, $\tilde{\sigma}=7$, which strongly satisfies Assumption 1. We examine alternative parametrizations in the full version of the model, in section 5. Qualitatively, the precise values of the shocks' standard errors do not matter, so we set them all to 0.1, except $\sigma_{\theta}$, which is set to 0.05 in the benchmark in order to generate significant boom and bust dynamics.

The left panels in Figure 3 show the effect of a unitary shock on fundamental demand $\psi$ on the average forecast, supply and mark-up in period 1 and 2 , for

\footnotetext{
${ }^{13}$ See Ruhl (2008) and Imbs and Mejean (2009).

${ }^{14}$ See Attanasio and Weber (1993) and Vissing-Jörgensen and Attanasio (2003).
} 
different values of $\sigma_{\theta}$. In this example, the first-best response of both the forecast and supply is 1 , and the first-best response of the mark-up is 0 . As stated in Lemma 1, this shock does not fully translate to $E_{1}(\psi)$ and $\hat{q}_{1}$, which respond positively but remain below 1 . As a result of excess demand, the mark-up increases in period 1. In period 2 , the forecast and supply get closer to 1 , as firms receive additional information through their mark-up. As a result, the mark-up gets closer to 0. As $\sigma_{\theta}$ decreases, information becomes more precise and the output and mark-up get closer to their first-best response.

Consider now the right panels of the figure, which represent the effect of an aggregate noise shock $\theta=1$. In the first period, $\theta=1$ is observationally equivalent to $\psi=1$, so it results in identical responses of $E_{1}(\psi)$ and $\hat{q}_{1}$. However, the response of output is now above its first-best value, which is zero. Goods are then in excess supply, which implies that the response of the mark-up is negative. Crucially, as explained above, the fact that the mark-up reacts differently after a fundamental and a noise shock explains why the forecasts can be reversed after a noise shock. In the second period, the forecast and supply turn negative in the second period, as expected. As $\sigma_{\theta}$ decreases, noise shocks generate more volatile booms and busts as firms tend to believe that signals are more likely to be driven by $\psi$.

The left panels of figure 4 show the effect of a fundamental shock $\psi=1$ on the average forecast and output, depending on aggregate congestion effects $\tilde{\sigma}$. In the first period, congestion does not affect the average forecast $E_{1}(\psi)$, but its effect on output $\hat{q}_{1}$ is increasing because strategic substitutability makes firms more sensitive to their private signal $\psi_{i}$. Notice that output is exactly equal to its certainty equivalent - the value of the forecast - when $\tilde{\sigma}=1$, that is, when there are no strategic effects. In the second period, the effect of congestion is non-monotonic. When $\tilde{\sigma}=1$, the mark-up signal is not blurred by aggregate supply so the inference of $\psi$ is straightforward. When $\tilde{\sigma}$ gets larger or lower than 1, the period 2 forecast and output become lower than their first-best value. This is because the mark-up now reacts (positively or negatively) to aggregate supply, which makes the inference of $\psi$ more difficult.

Similarly, the right panels of figure 4 show how the effect of a noise shock $\theta=1$ on forecasts and outputs is affected by aggregate congestion effects $\tilde{\sigma}$. In the first period, the response of output gets further away from its first-best value, which is zero, as congestion $\tilde{\sigma}$ increases due to the strategic use of information. In the second period, the effect of congestion $\tilde{\sigma}$ is also non-monotonous. For low values of $\tilde{\sigma}$, stronger congestion exacerbates the negative effect of overproduction on the mark-up, which is interpreted by firms as a negative signal on the state of demand. But as congestion effects become stronger, it is more likely that a low mark-up reflects overproduction, so firms tend not to believe that demand is low. In the case where $\tilde{\sigma}<1$, the firm still revises its forecasts of $\psi$ downwards, but 
not enough to undershoot the fundamental value, which is zero.

\section{Full monetary version}

In this section, we solve the full monetary version of the model, that is with prices specified in nominal terms, which means that nominal wages are now part of the firms' information set. We show that the forecasts of $\psi$ become more precise when firms are able to observe the nominal wage, but they are still imperfect because of monetary shocks. The dynamics still features boom-and-bust cycles.

\subsection{Labor market and information structure}

At the beginning of period, the household establishes competitively with firms the amount of labor that she will provide against a pre-specified nominal wage $w_{t}$. Firms therefore observe $w_{t}$ at the same time as they decide how much they produce. As a result of household's optimization, the nominal wage partly reveals the preference shock:

$$
w_{t}=\frac{\sigma-1}{\sigma} \hat{q}_{t}-\psi+m_{t}
$$

This equation is obtained from combining Equations (8) and (9). The nominal wage depends positively on the monetary shock $m_{t}$, negatively on the preference shock $\psi$ and positively on aggregate production $\hat{q}_{t}$ if the macro elasticity of labor supply $1 / \sigma$ is below one. Since the firm does not observe $m_{t}$ or $\hat{q}_{t}$ directly, the nominal wage will not perfectly reveal $\psi$.

Now that firms observe the nominal wage $w_{t}$, the information structure of the model is modified. At the beginning of period 1, firms still receive the exogenous signal $\psi_{i}$, so $\Omega_{i 1}=\left\{\psi_{i}, w_{1}\right\}$. In period 1 , they observe their nominal price $p_{i 1}$, so $\Omega_{i 2}=\left\{\psi_{i}, p_{i 1}, w_{1}, w_{2}\right\}$, which is equivalent to $\Omega_{i 2}=\left\{\psi_{i}, p_{i 1}-w_{1}, w_{1}, w_{2}\right\}$.

Notice that the case with a unitary elasticity of labor, that is with $\sigma=1$, is simpler since in that case $w_{t}$ does not depend on $\hat{q}_{t}$ :

$$
w_{t}=-\psi+m_{t}
$$

We solve this special case analytically and show that the results of the simple version of the model are not affected. We then solve the more general case numerically.

\subsection{Analytical results with $\sigma=1$}

In the first period, firms can use two signals: $\psi_{i}=\psi+\theta+\lambda_{i}$ and $w_{1}=$ $-\psi+m_{1}$. The resulting forecasts and supply are affected as described by the 
following Proposition (see proof in the Appendix):

Proposition 3 (Period-1 production) In period 1, optimal supply by firm $i$ obeys to:

$$
\hat{q}_{i 1}=K_{\psi}^{*} \psi_{i}-K_{w}^{*} w_{1}
$$

where $0<K_{\psi}^{*}<1,0<K_{w}^{*}<1$. Besides, we have $K_{\psi}^{*}<K_{\psi}$, and $K_{\psi}<$ $K_{\psi}^{*}+K_{w}^{*}<1$. At the aggregate level, firms produce the following quantities:

$$
\hat{q}_{1}=\left[K_{\psi}^{*}+K_{w}^{*}\right] \psi+K_{\psi}^{*}\left(\theta+\lambda_{i}\right)-K_{w}^{*} m_{1}
$$

As in the simple version of the model, firms under-react to the fundamental shock $\psi$ and over-react to the noise shock $\theta$, since $K_{\psi}^{*}+K_{w}^{*}<1$ and $K_{\psi}^{*}>0$. But because they receive an additional signal on $\psi$, they react more to $\psi$ and less to $\theta$, as $K_{\psi}^{*}+K_{w}^{*}>K_{\psi}$ and $K_{\psi}^{*}<K_{\psi}$.

At the end of period 1, firms' mark-ups constitute a new signal. As Equation (16) is still valid, we can derive the following corollary:

Corollary 4 The information available at the beginning of period 2 is summarized by four independent signals of $\psi$ : two monetary signals $-w_{1}=\psi-m_{1}$ and $-w_{2}=$ $\psi-m_{2}$ and two real signal, a public signal $s^{*}$ and a private signal $x_{i}^{*}$, defined as follows:

$$
\begin{aligned}
& s^{*}=\psi-\omega_{\theta}^{*} \theta \\
& x_{i}^{*}=\psi+\omega_{\lambda}^{*} \lambda_{i}
\end{aligned}
$$

with $\omega_{\theta}^{*}=(\tilde{\sigma}-1) K_{\psi}^{*} /\left[\tilde{\sigma}-(\tilde{\sigma}-1) K_{\psi}^{*}\right]$ and $\omega_{\lambda}^{*}=\omega_{\theta}^{*} /\left(1+\omega_{\theta}^{*}\right)$. Under Assumption $1, \omega_{\theta}^{*}>0$ and $\omega_{\theta}^{*}<\omega_{\theta}, \omega_{\lambda}^{*}<\omega_{\lambda}$. Besides, $\omega_{\theta}^{*}$ is increasing in $\tilde{\sigma}$.

Proof. Here again $s^{*}$ is obtained simply by normalizing the filtered mark-up and $x_{i}^{*}$ is obtained by combining $s^{*}$ with $\psi_{i}$. $\omega_{\theta}^{*}<\omega_{\theta}$ follows from $K_{\psi}^{*}<K_{\psi}$ and $\omega_{\lambda}^{*}<\omega_{\lambda}$ follows from $\omega_{\theta}^{*}<\omega_{\theta}$.

Since $\omega_{\theta}^{*}<\omega_{\theta}$ and $\omega_{\lambda}^{*}<\omega_{\lambda}, x_{i}^{*}$ and $s^{*}$ are more precise signals of $\psi$ than $x_{i}$ and $s$. Besides, firms can use two additional signals of $\psi$, the nominal signals $-w_{1}=\psi-m_{1}$ and $-w_{2}=\psi-m_{2}$. In the monetary version of the model, firms have more precise information on $\psi$. However, we still have that $\theta$ affects negatively the public signal of $\psi$. Supply in period 2 is therefore only affected quantitatively, as shown in the following Proposition (see proof in the Appendix):

Proposition 4 (Period-2 production) In period 2, optimal supply by firm $i$ obeys to:

$$
\hat{q}_{i 2}=F_{x}^{*} x_{i}^{*}+F_{s}^{*} s^{*}-F_{w}^{*}\left(w_{1}+w_{2}\right)
$$

where $0<F_{w}^{*}<1,0<F_{x}^{*}<1$ and $0<F_{s}^{*}<1$. Since $s^{*}$ and $x_{i}^{*}$ are more precise signals of $\psi$ than $s$ and $x_{i}$, but are used along with other signals, $F_{s}^{*}$ and 
$F_{x}^{*}$ can be either lower or higher than $F_{s}$ and $F_{x}$. However, we have $F_{x}+F_{s}<$ $F_{x}^{*}+F_{s}^{*}+2 F_{w}^{*}<1$. At the aggregate level, firms produce the following quantities:

$$
\hat{q}_{2}=\left[F_{x}^{*}+F_{s}^{*}+2 F_{w}^{*}\right] \psi-F_{s}^{*} \omega_{\theta}^{*} \theta-F_{w}^{*}\left(m_{1}+m_{2}\right)
$$

As in the simple model, the contribution of $\theta$ to the public signal $s^{*}$ is negative when congestion effects are present, so the effect of $\theta$ on $q_{i 2}$ is still negative. Again, the bust generated by $\theta$ can still be potentially large, as implied by the following corollary (see proof in the Appendix):

Corollary 5 As $\sigma_{\theta}^{2}$ goes to zero, $-F_{s}^{*} \omega_{\theta}^{*}$ goes to $-(\tilde{\sigma}-1) \sigma_{\psi}^{2} /\left(\sigma_{\psi}^{2}+\sigma_{\lambda}^{2}+\sigma_{\psi}^{2} \sigma_{\lambda}^{2} / \sigma_{m}^{2}\right)$.

Therefore, following a noise-driven boom, the bust can be arbitrarily large as aggregate noise shock are unlikely and congestion effects are strong.

\subsection{Numerical results}

Here we analyze numerical simulations to show the role of $\sigma_{m}, \sigma_{\theta}$ and $\sigma$. For the cases where $\sigma \neq 1$, we simulate the model numerically. The numerical simulation method is described in the Appendix.

Figure 5 shows the effect of unitary shocks on $\psi$ and $\theta$ on the forecast, output and mark-ups in period 1 and 2, for different values of $\sigma_{m}$ and $\sigma_{\theta}$. The baseline calibration follows Table 1. In particular, we can compare the baseline monetary model, with $\sigma_{m}=0.1$, to the simple model, which is equivalent to the monetary model with $\sigma_{m}$ going to infinity. The results are qualitatively similar but are quantitatively different. In the monetary model, the forecasts, quantities and mark-ups are closer to their first-best values than in the simple model. This is because the nominal wages provide additional information to firms about the underlying shocks. As a result, the boom-and-bust dynamics arising from an aggregate noise shock $\theta=1$ is milder. However, as stated in Corollary 5 and illustrated in the figure in the case $\sigma_{\theta}=0.01$, boom-and-bust episodes are still magnified when noise shocks are relatively unlikely.

The degree of real rigidities in the economy, which corresponds to $1 / \sigma$ in our model, depends in general on the structure of the economy. ${ }^{15}$ There is a lot of disagreement in the literature on its precise value. Richer models find estimates of the inverse of real rigidities ( $\sigma$ in our model) that vary between 0.3 to $3 .{ }^{16}$ Our

\footnotetext{
${ }^{15}$ Here we use the term "real rigidities" in the same way as the New Keynesian literature, that is, as the elasticity of the marginal cost to the output gap. In our model, real rigidities are therefore equal to the inverse of $\sigma$, the macro elasticity of labor supply to the real wage.

${ }^{16}$ For example, this value is equal to 0.33 in Dotsey and King (2006), to 0.34 in Smets and Wouters (2007) to 2.25 in the baseline parametrization used by Chari et al. (2000) and to 3 in Galí (2009).
} 
baseline parametrization falls within this range. Although $\tilde{\sigma}$ is lower when $\sigma$ is equal to the lower bound 0.3 , it is still above one with $1 / \rho=7 .{ }^{17}$ In Figure 6 , we simulate the baseline along with the two polar cases $\sigma=0.3$ and $\sigma=3$.

In the case where $\sigma=3$, the forecast reacts less to the fundamental shock as the response of the nominal wage to $\psi$ is dampened. Indeed, a positive demand shock $\psi$ has a negative direct impact on the wage, but with a low macro elasticity of labor (a high $\sigma$ ), there is a positive indirect impact, as the real wage has to increase more as a response to higher labor demand. This mitigates the negative response of the nominal wage to $\psi$. When $\sigma$ is higher, firms are therefore less able to forecast $\psi$, both in the first and second period. The opposite happens with $\sigma=0.3$. Regarding the noise shock, a higher $\sigma$ makes the boom in expectations milder but the bust stronger. Indeed, in the first period, the nominal wage reacts positively to the increase in labor demand by firms, which can also signal a low fundamental demand. As a result, there is a downward bias in the demand forecasts. This effect is reversed with a lower $\sigma$.

\subsection{Credit}

We now introduce credit in order to account for the typical surge in credit that characterizes booms and busts. To do so, we introduce a non-produced traded good $X$, in fixed supply $\bar{X}$ in the country but in infinite supply from the rest of the world. Households can exchange good $X$ with the rest of the world and save or borrow vis-à-vis the rest of the world. Congestion effects and imperfect competition still affect the nontradable sector where firms produce differentiated goods as described in Section 2. In this extension, we also endogeneize noise shocks by introducing an initial period 0 , where temporary aggregate and idiosyncratic demand shocks can appear. These temporary demand shocks generate noise because firms cannot distinguish them from the permanent demand shock. Therefore, an aggregate temporary demand shock will generate credit among households and in the same time mislead firms about the true value of the permanent shock.

We introduce a demand for a traded good by amending the model of Section 2 in the following way. The specification of the utility (2) becomes for $t=1,2$ :

$$
U_{t}=\Psi \log \left(Q_{t}^{\mu} X_{t}^{1-\mu}\right)-L_{t}
$$

with $0<\mu<1 . \mu$ is the share of nontradable goods in consumption. When $\mu=1$,

\footnotetext{
${ }^{17}$ As argued by Woodford (2003), the ability of labor to move freely from one sector to the other is crucial to determine the degree of real rigidities. The degree of real rigidities should therefore be high in the short-run, when labor is not mobile, and low in the long-run, when labor is mobile. Since we consider the medium-run horizon, this should point to a relatively low degree of real rigidities, hence to a high $\sigma$.
} 
the utility function boils down to (2) where $\gamma=1$ and $\eta=0$. $Q$ now refers to the consumption of non-traded goods. In the initial period $t=0$, utility is now:

$$
U_{0}=\Psi \Theta \log \left(Q_{t}^{\mu} X_{t}^{1-\mu}\right)-L_{t}
$$

with $Q_{0}=\left(\int_{0}^{1} \Lambda_{i} Q_{i}^{1-\rho} d i\right)^{\frac{1}{1-\rho}} \cdot \theta=\log (\Theta)$ is a temporary aggregate demand shock and $\lambda_{i}=\log \left(\Lambda_{i}\right)$ is a temporary idiosyncratic demand shock, where $\theta$ and $\lambda_{i}$ have the same characteristics as described in Section 2. The household now maximizes $U=U_{0}+\beta U_{1}+\beta^{2} U_{2}$ subject to the budget constraints:

$\int_{0}^{1} P_{i t} Q_{i t} d i+M_{t}+P_{t}^{x} X_{t}+r P_{t}^{x} D_{t-1}=W_{t} L_{t}+\int_{0}^{1} \Pi_{i t} d i+M_{t-1}+T_{t}+P_{t}^{x} \bar{X}+P_{t}^{x} D_{t}$

for $t=0,1,2$. $P_{t}^{x}$ is the price of good $X$ in nominal terms and $D_{t}$ is international borrowing in terms of tradable goods, which yields interest $r=1 / \beta$. Households now can trade intertemporally with the rest of the world through $D$. We assume that they start with no international debt so $D_{-1}=0$.

The cash-in-advance constraint and the government budget constraint are the same as before, which yields (9).

The aggregate and individual demands remain as described in Equations (7) and (8) in periods 1 and 2, except that we have $\gamma=1$ and $\eta=0$. In period 0 , they are additionally affected by the aggregate and individual transitory shocks $\theta$ and $\lambda_{i}$ :

$$
\begin{gathered}
q_{i 0}=q_{0}-\frac{1}{\rho}\left[p_{i 0}-p_{0}-\lambda_{i 0}\right] \\
w_{0}-p_{0}=q_{0}-\psi-\theta
\end{gathered}
$$

Ex ante, firms observe nominal wages $w_{0}=m_{0}-\psi-\theta$, so they produce $q_{i}=$ $q=-h w_{0}$, where $h=\sigma_{\psi}^{2} /\left(\sigma_{\psi}^{2}+\sigma_{\theta}^{2}+\sigma_{m}^{2}\right)$. As a result, in period 0 , they observe mark-ups:

$$
p_{i 0}-w_{0}=\psi+\theta+\lambda_{i}+h w_{0}
$$

which, combined with $w_{0}$ gives the initial signal $\psi_{i}$ :

$$
\psi_{i}=p_{i 0}-w_{0}-h w_{0}=\psi+\theta+\lambda_{i}
$$

Period-0 mark-ups are therefore an imperfect signal of the permanent demand shock $\psi$. This signal is perturbed by the aggregate and idiosyncratic demand shocks $\theta$ and $\lambda_{i}$. This gives an economic significance to the initial signal $\psi_{i}$ in the baseline model. Regarding the dynamics of the non-traded good in period 1 and 2 , the only difference with the baseline model with $\gamma=1$ and $\eta=0$ is that agents start period 1 with an additional nominal signal $w_{0}$. 
We derive the following Proposition (see proof in the Appendix):

Proposition 5 (Boom-busts and capital flows) A positive aggregate transitory demand shock $\theta>0$ generates capital inflows in period 0 , a boom in period 1 and, under Assumption 1, a bust in period 2. A positive aggregate permanent shock $\psi>0$ generates no capital flows and a sustained boom in period 1 and 2.

A temporary demand shock $\theta$ generates a demand boom in period 0 which makes households increase their borrowing. This same temporary demand boom makes firms mistakenly interpret it as a permanent boom, making them overoptimistic, which triggers a boom-and-bust dynamics in the non-tradable sector. A permanent increase in demand does not generate a boom-and-bust dynamics since firms are confirmed in their beliefs. At the same time, households do not borrow as the shock is permanent.

\section{Conclusion}

This paper has shown that, in a model where agents have imperfect common knowledge and learn from prices, fundamental shocks lead to standard learning dynamics while noise shocks lead to boom-and-bust dynamics. These dynamics are rooted in the lack of communication between agents and the fact that, due to market timing and to the monetary nature of transactions, prices do not communicate enough information.

While the focus of the literature is on the channel from information to equilibrium variables, this paper shows in a simple model that studying the way equilibrium variables affect information generates new insights. In more general frameworks, this approach is subject to technical difficulties, that are now reduced thanks to the contributions of Nimark (2011) and Rondina and Walker (2012). We believe that these recent methodological advances open an avenue for future research in that direction.

In particular, it would be interesting to investigate whether the central bank can improve allocations by using prices to communicate its own information to agents. So far, the literature on imperfect common knowledge has highlighted the role of policy in improving the private use of information by changing the agents' incentives through both fiscal and monetary policy. ${ }^{18}$ We believe that the communication role of prices (and other market-generated information that is affected by policy) has the potential to alter standard monetary doctrines. Indeed, price stabilization might not be optimal if prices convey information. This is left for future research.

\footnotetext{
${ }^{18}$ See Adam (2007), Angeletos and Pavan (2007), Angeletos and Pavan (2009), Lorenzoni (2010), Amador and Weill (2010), Paciello and Wiederholt (2011) and Angeletos and La'o (2012).
} 


\section{References}

Adam, Klaus (2007), 'Optimal monetary policy with imperfect common knowledge', Journal of Monetary Economics 54(2), 267-301.

Amador, Manuel and Pierre-Olivier Weill (2010), 'Learning from prices: Public communication and welfare', Journal of Political Economy 118(5), 866-907.

Amador, Manuel and Pierre-Olivier Weill (2012), 'Learning from private and public observations of others'actions', Journal of Economic Theory 147(3), 910-940.

Angeletos, George-Marios and Alessandro Pavan (2007), 'Efficient use of information and social value of information', Econometrica 75(4), 1103-1142.

Angeletos, George-Marios and Alessandro Pavan (2009), 'Policy with dispersed information', Journal of the European Economic Association 7(1), 11-60.

Angeletos, George-Marios, Guido Lorenzoni and Alessandro Pavan (2010), Beauty contests and irrational exuberance: A neoclassical approach, NBER Working Papers 15883, National Bureau of Economic Research, Inc.

Angeletos, George-Marios and Jennifer La'O (2009), Noisy business cycles, Working Paper 14982, National Bureau of Economic Research.

Angeletos, George-Marios and Jennifer La'o (2012), Optimal monetary policy with informational frictions, mimeo.

Attanasio, Orazio P and Guglielmo Weber (1993), 'Consumption growth, the interest rate and aggregation', Review of Economic Studies 60(3), 631-49.

Beaudry, Paul and Franck Portier (2004), 'An exploration into pigou's theory of cycles', Journal of Monetary Economics 51(6), 1183-1216.

Beaudry, Paul and Franck Portier (2006), 'Stock prices, news, and economic fluctuations', American Economic Review 96(4), 1293-1307.

Blanchard, Olivier J., Jean-Paul L'Huillier and Guido Lorenzoni (2009), News, noise, and fluctuations: An empirical exploration, NBER Working Papers 15015, National Bureau of Economic Research, Inc.

Bloom, Nicholas, Max Floetotto, Nir Jaimovich, Itay Saporta-Eksten and Stephen J. Terry (2012), Really uncertain business cycles, NBER Working Papers 18245, National Bureau of Economic Research, Inc. 
Chari, V. V., Patrick J. Kehoe and Ellen R. McGrattan (2000), 'Sticky price models of the business cycle: Can the contract multiplier solve the persistence problem?', Econometrica 68(5), 1151-1180.

Christiano, Lawrence, Cosmin Ilut, Roberto Motto and Massimo Rostagno (2008), Monetary policy and stock market boom-bust cycles, Working Paper Series 955, European Central Bank.

Council of Economic Advisors (1954), Economic report of the president, 1954, Technical report, Federal Reserve Archive.

Dotsey, Michael and Robert G. King (2006), 'Pricing, production, and persistence', Journal of the European Economic Association 4(5), pp. 893-928.

Frydman, Roman and Edmund S. Phelps (1984), Cambridge University Press.

Gaballo, Gaetano (2013), Price dispersion and private uncertainty, mimeo.

Galí, J. (2009), Monetary Policy, Inflation, and the Business Cycle: An Introduction to the New Keynesian Framework, Princeton University Press.

Graham, Liam and Stephen Wright (2010), 'Information, heterogeneity and market incompleteness', Journal of Monetary Economics 57(2), 164 - 174.

Hellwig, Christian (2006), Monetary business cycle models: Imperfect information (review article, march 2006), UCLA Economics Online Papers 377, UCLA Department of Economics.

Hellwig, Christian and Venky Venkateswaran (2009), 'Setting the right prices for the wrong reasons', Journal of Monetary Economics 56, Supplement(0), S57 $-\mathrm{S} 77$.

Hoberg, Gerard and Gordon Phillips (2010), 'Real and financial industry booms and busts', The Journal of Finance 65(1), 45-86.

Imbs, Jean and Isabelle Mejean (2009), Elasticity optimism, CEPR Discussion Papers 7177, C.E.P.R. Discussion Papers.

Jaimovich, Nir and Sergio Rebelo (2009), 'Can news about the future drive the business cycle?', American Economic Review 99(4), 1097-1118.

Keynes, J.M. (2006), General Theory Of Employment, Interest And Money, Atlantic Publishers \& Distributors (P) Limited. 
Lambertini, Luisa, Caterina Mendicino and Maria Teresa Punzi (2011), Leaning against boom-bust cycles in credit and housing prices, Working Papers 201101, Center for Fiscal Policy, Swiss Federal Institute of Technology Lausanne.

Lorenzoni, Guido (2009), 'A theory of demand shocks', American Economic Review 99(5), 2050-84.

Lorenzoni, Guido (2010), 'Optimal monetary policy with uncertain fundamentals and dispersed information', Review of Economic Studies 77(1), 305-338.

Lucas, Robert Jr. (1972), 'Expectations and the neutrality of money', Journal of Economic Theory 4(2), 103-124.

Mulligan, Casey (1999), Substition over time: Another look at life-cycle labor supply, in 'NBER Macroeconomics Annual 1998, volume 13', National Bureau of Economic Research, Inc, pp. 75-152.

Nimark, Kristoffer (2011), Dynamic higher order expectations, Technical report, Department of Economics and Business, Universitat Pompeu Fabra.

Paciello, Luigi and Mirko Wiederholt (2011), Exogenous information, endogenous information and optimal monetary policy, EIEF Working Paper Series 1104, Einaudi Institute for Economics and Finance (EIEF).

Pigou, A.C. (1927), Industrial fluctuations, Macmillan and co., limited.

Ramey, Valerie and Christofer Nekarda (2010), The cyclical behavior of the pricecost markup, mimeo.

Rondina, Giacomo and Todd Walker (2012), Information equilibria in dynamic economies with dispersed information, mimeo, University of San Diego.

Ruhl, Kim J. (2008), Solving the Elasticity Puzzle in International Economics, mimeo.

Sargent, Thomas J. (1991), 'Equilibrium with signal extraction from endogenous variables', Journal of Economic Dynamics and Control 15(2), 245 - 273.

Sims, Christopher (2003), 'Implications of rational inattention', Journal of Monetary Economics 50(3), 665-690.

Smets, Frank and Rafael Wouters (2007), 'Shocks and frictions in us business cycles: A bayesian dsge approach', American Economic Review 97(3), 586-606.

Townsend, Robert M (1983), 'Forecasting the forecasts of others', Journal of Political Economy 91(4), 546-88. 
Vissing-Jörgensen, Annette and Orazio P. Attanasio (2003), 'Stock-market participation, intertemporal substitution, and risk-aversion', American Economic Review 93(2), 383-391.

Woodford, M. (2003), Interest and Prices: Foundations of a Theory of Monetary Policy, Princeton University Press.

Woodford, Michael (2001), Imperfect common knowledge and the effects of monetary policy, NBER Working Papers 8673, National Bureau of Economic Research, Inc.

\section{A Proofs}

Denote by $\xi_{i}$ a gaussian vector of shocks of size $N$, where the $n$ first elements are aggregate shocks and the $N-n$ last elements are idiosyncratic shocks, and $S_{i}$ a vector of signals of size $K$ such that there exists a $(N, K)$ matrix $H$ such that:

$$
S_{i}=H^{\prime} \xi_{i}
$$

We denote by $\tilde{H}$ the $(N, K)$ matrix such that all the $n$ first lines are equal to the $n$ first lines of $H$ and the $N-n$ last lines are equal to zero. Let $P$ be a $(N, K)$ matrix such that:

$$
E\left(\xi_{i} \mid S_{i}\right)=P S_{i}
$$

The following lemma will be useful in proving several propositions:

Lemma 3 Consider the following equation:

$$
\hat{q}_{i}=\left[\tilde{\sigma} X^{\prime} E\left(\xi_{i} \mid S_{i}\right)-(\tilde{\sigma}-1) E\left(\hat{q} \mid S_{i}\right)\right]
$$

where $X$ is a vector of size $N$. Then, if $I+(\tilde{\sigma}-1) \tilde{H}^{\prime} P$ is invertible, we have:

$$
\hat{q}_{i}=A S_{i}
$$

where $A$ is a size-K row vector such that:

$$
A=\tilde{\sigma} X^{\prime} P\left[I+(\tilde{\sigma}-1) \tilde{H}^{\prime} P\right]^{-1}
$$

\section{Proof of Lemma 3.}

We use the method of undetermined coefficients to solve for $A$. We first form the educated guess that there exist a size- $K$ row vector $A$ such that

$$
\hat{q}_{i}=A S_{i}
$$


then, using Equation (26), we obtain

$$
\hat{q}_{i}=A H^{\prime} \xi_{i}
$$

Hence, aggregating across firms, taking expectations and using Equation (27):

$$
E\left(\hat{q} \mid S_{i}\right)=A \tilde{H}^{\prime} E\left(\xi_{i} \mid S_{i}\right)=A \tilde{H}^{\prime} P S_{i}
$$

Replacing in Equation (28):

$$
\hat{q}_{i}=\left[\tilde{\sigma} X^{\prime} P S_{i}-(\tilde{\sigma}-1) A \tilde{H}^{\prime} P S_{i}\right]=\left[\tilde{\sigma} X^{\prime} P-(\tilde{\sigma}-1) A \tilde{H}^{\prime} P\right] S_{i}
$$

Using the guess, we can write:

$$
A=\tilde{\sigma} X^{\prime} P-(\tilde{\sigma}-1) A \tilde{H}^{\prime} P
$$

If $I+(\tilde{\sigma}-1) \tilde{H}^{\prime} P$ is invertible, we can solve for $A$ and obtain (29).

\section{Proof of Proposition 1.}

According to Equation (10), $\hat{q}_{i 1}$ follows (28) with $S_{i}=\psi_{i}, \xi_{i}=\left(\begin{array}{lll}\psi & \theta & \lambda_{i}\end{array}\right)^{\prime}$ and $X=\left(\begin{array}{lll}1 & 0 & 0\end{array}\right)^{\prime}$. Besides, $S_{i}$ follows $(26)$ with $H=\left(\begin{array}{lll}1 & 1 & 1\end{array}\right)^{\prime}$ and $\tilde{H}=\left(\begin{array}{lll}1 & 1 & 0\end{array}\right)^{\prime}$;

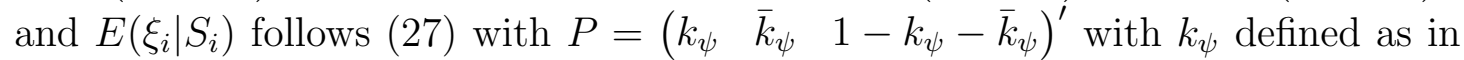
Lemma 1 and $\bar{k}_{\psi}=\sigma_{\theta}^{2} /\left(\sigma_{\psi}^{2}+\sigma_{\theta}^{2}+\sigma_{\lambda}^{2}\right)$. Therefore, applying Lemma 3, we obtain:

$$
K_{\psi}=A=\frac{\tilde{\sigma} k_{\psi}}{1+(\tilde{\sigma}-1)\left(k_{\psi}+\bar{k}_{\psi}\right)}=k_{\psi}\left(1+\frac{(\tilde{\sigma}-1)\left(1-k_{\psi}-\bar{k}_{\psi}\right)}{1+(\tilde{\sigma}-1)\left(k_{\psi}+\bar{k}_{\psi}\right)}\right)
$$

We have: $K_{\psi}=\tilde{\sigma} k_{\psi} /\left[\tilde{\sigma} k_{\psi}+\tilde{\sigma} \bar{k}_{\psi}+\left(1-k_{\psi}-\bar{k}_{\psi}\right)\right]$, which implier $0<K_{\psi}<1$ as $k_{\psi}+\bar{k}_{\psi}<1$. Besides, we have $k_{\psi}+\bar{k}_{\psi}<1$ and under Assumption $1 \tilde{\sigma}>1$, so $K_{\psi}>k_{\psi}$.

\section{Proof of Lemma 2.}

The standard signal extraction formula gives us that $E_{i 2}(\psi)=f_{x} x_{i}+f_{s} s$ with

$$
\begin{aligned}
& f_{x}=\frac{\left(\omega_{\lambda} \sigma_{\lambda}\right)^{-2}}{\left(\sigma_{\psi}\right)^{-2}+\left(\omega_{\theta} \sigma_{\theta}\right)^{-2}+\left(\omega_{\lambda} \sigma_{\lambda}\right)^{-2}}=\frac{\left(1+\omega_{\theta}\right)^{2} \sigma_{\psi}^{2} \sigma_{\theta}^{2}}{\left(1+\omega_{\theta}\right)^{2} \sigma_{\psi}^{2} \sigma_{\theta}^{2}+\sigma_{\psi}^{2} \sigma_{\lambda}^{2}+\omega_{\theta}^{2} \sigma_{\theta}^{2} \sigma_{\lambda}^{2}} \\
& f_{s}=\frac{\left(\omega_{\theta} \sigma_{\theta}\right)^{-2}}{\left(\sigma_{\psi}\right)^{-2}+\left(\omega_{\theta} \sigma_{\theta}\right)^{-2}+\left(\omega_{\lambda} \sigma_{\lambda}\right)^{-2}}=\frac{\sigma_{\psi}^{2} \sigma_{\lambda}^{2}}{\left(1+\omega_{\theta}\right)^{2} \sigma_{\psi}^{2} \sigma_{\theta}^{2}+\sigma_{\psi}^{2} \sigma_{\lambda}^{2}+\omega_{\theta}^{2} \sigma_{\theta}^{2} \sigma_{\lambda}^{2}}
\end{aligned}
$$

where we used $\omega_{\lambda}=\omega_{\theta} /\left(1+\omega_{\theta}\right)$. Obviously, $0<f_{x}<1,0<f_{s}<1$ and $f_{x}+f_{s}<1$. Besides, we can show that $f_{x}+f_{s}>k_{\psi}$. Indeed, using the definitions of $f_{x}, f_{s}$ and 
$k_{\psi}$, we can show that this is equivalent to: $\omega_{\theta}^{2} \sigma_{\theta}^{2} \sigma_{\lambda}^{2}<\left(\sigma_{\theta}^{2}+\sigma_{\lambda}^{2}\right)\left(\left(1+\omega_{\theta}\right)^{2} \sigma_{\theta}^{2}+\sigma_{\lambda}^{2}\right)$. A sufficient condition for this to be true is $\omega_{\theta}<1$, which is always the case since $K_{\psi}<1$ and $\tilde{\sigma}>0$. Finally, we can show that $f_{s}$ is decreasing in $K_{\psi}$ as $\omega_{\theta}<1$. Since $\omega_{\theta}$ is increasing in $\tilde{\sigma}$, then $f_{s}$ is decreasing in $\tilde{\sigma}$.

\section{Proof of Corollary 2.}

First, we examine the behavior of the coefficient $\omega_{\theta}$ as $\sigma_{\theta}$ goes to zero. From the definition of $K_{\psi}$ given in Proposition 1, we have:

$$
K_{\psi}=k_{\psi}\left(1+\frac{(\tilde{\sigma}-1)\left(1-k_{\psi}-\bar{k}_{\psi}\right)}{1+(\tilde{\sigma}-1)\left(k_{\psi}+\bar{k}_{\psi}\right)}\right)
$$

with $k_{\psi}=\sigma_{\psi}^{2} /\left(\sigma_{\psi}^{2}+\sigma_{\theta}^{2}+\sigma_{\lambda}^{2}\right)$ and $\bar{k}_{\psi}=\sigma_{\theta}^{2} /\left(\sigma_{\psi}^{2}+\sigma_{\theta}^{2}+\sigma_{\lambda}^{2}\right)$.

When $\sigma_{\theta}$ goes to zero, $k_{\psi}$ goes to $k_{\psi}=\sigma_{\psi}^{2} /\left(\sigma_{\psi}^{2}+\sigma_{\lambda}^{2}\right)$ and $\bar{k}_{\psi}$ goes to zero. As a result, $K_{\psi}$ goes to $\tilde{\sigma} \sigma_{\psi}^{2} /\left(\tilde{\sigma} \sigma_{\psi}^{2}+\sigma_{\lambda}^{2}\right)$. Hence, using the definition of $\omega_{\theta}$ given in Corollary 1 , we can show that $\omega_{\theta}$ goes to $(\tilde{\sigma}-1) \sigma_{\psi}^{2} /\left(\sigma_{\psi}^{2}+\sigma_{\lambda}^{2}\right)$.

Using the definition of $f_{s}$ given in the proof of Lemma 2 , it is straightforward to see that $f_{s}$ goes to 1 as $\sigma_{\theta}$ goes to zero. As a consequence, $-f_{s} \omega_{\theta}$ goes to $-(\tilde{\sigma}-1) \sigma_{\psi}^{2} /\left(\sigma_{\psi}^{2}+\sigma_{\lambda}^{2}\right)$.

\section{Proof of Proposition 2.}

According to Equation (10), $\hat{q}_{i 2}$ follows (28) with $S_{i}=\left(\begin{array}{ll}s & x_{i}\end{array}\right)^{\prime}$,

$$
\xi_{i}=\left(\begin{array}{c}
\psi \\
-\omega_{\theta} \theta \\
\omega_{\lambda} \lambda_{i}
\end{array}\right)
$$

and $X=\left(\begin{array}{lll}1 & 0 & 0\end{array}\right)^{\prime}$. Besides, $S_{i}$ follows (26) with

$$
H=\left(\begin{array}{ll}
1 & 1 \\
1 & 0 \\
0 & 1
\end{array}\right)
$$

and

$$
\tilde{H}=\left(\begin{array}{ll}
1 & 1 \\
1 & 0 \\
0 & 0
\end{array}\right)
$$


and $E\left(\xi_{i} \mid S_{i}\right)$ follows (27) with

$$
P=\left(\begin{array}{cc}
f_{s} & f_{x} \\
1-f_{s} & -f_{x} \\
-f_{s} & 1-f_{x}
\end{array}\right)
$$

with $f_{s}$ and $f_{x}$ defined as in Lemma 2. Therefore, applying Lemma 3, we obtain:

$$
\left(\begin{array}{c}
F_{s} \\
F_{x}
\end{array}\right)=A^{\prime}=\left(\begin{array}{c}
\frac{f_{s}}{1+(\tilde{\sigma}-1) f_{x}} \\
\frac{\tilde{\sigma} f_{x}}{1+(\tilde{\sigma}-1) f_{x}}
\end{array}\right)=\left(\begin{array}{c}
f_{s}\left(1-\frac{(\tilde{\sigma}-1) f_{x}}{1+(\tilde{\sigma}-1) f_{x}}\right) \\
f_{x}\left(1+\frac{(\tilde{\sigma}-1)\left(1-f_{x}\right)}{1+(\tilde{\sigma}-1) f_{x}}\right)
\end{array}\right)
$$

We have $0<f_{x}<1$ and according to Assumption 1, we have $\tilde{\sigma}>1$, so $F_{x}>$ $f_{x}$ and $F_{s}<f_{s}$. Besides, one can show that $F_{x}+F_{s}>K_{\psi}$. Indeed, using the definitions of $F_{x}, F_{s}, K_{\psi}$ and $\omega_{\lambda}$, we can show that this is equivalent to: $\tilde{\sigma} \omega_{\theta}^{2} \sigma_{\theta}^{2} \sigma_{\lambda}^{2}<\left(\tilde{\sigma} \sigma_{\theta}^{2}+\sigma_{\lambda}^{2}\right)\left(\tilde{\sigma}\left(1+\omega_{\theta}\right)^{2} \sigma_{\theta}^{2}+\sigma_{\lambda}^{2}\right)$. A sufficient condition for this to be true is $\omega_{\theta}<1$, which is always the case since $K_{\psi}<1$ and $\tilde{\sigma}>0$. Finally, we have $F_{x}+F_{s}=\left(f_{s}+\tilde{\sigma} f_{x}\right) /\left(1-f_{x}+\tilde{\sigma} f_{x}\right)$. Since $f_{x}+f_{s}<1$, then $F_{x}+F_{s}<1$.

\section{Proof of Corollary 3.}

Using the definition of $f_{s}$ given in the proof of Lemma 2, it is straightforward to see that $f_{s}$ goes to 1 and $f_{x}$ goes to zero as $\sigma_{\theta}$ goes to zero. As a result, following the definition of $F_{s}$ given in the proof of Proposition 2, we show that $F_{s}$ goes to $f_{s}$ as $\sigma_{\theta}$ goes to zero.

Hence, as $\sigma_{\theta}$ goes to zero, $-F_{s} \omega_{\theta}$ goes to $-f_{s} \omega_{\theta}$ which, according to Corollary 2 , goes to $-(\tilde{\sigma}-1) \sigma_{\psi}^{2} /\left(\sigma_{\psi}^{2}+\sigma_{\lambda}^{2}\right)$.

Proof of Proposition 3.

According to Equation (10), $\hat{q}_{i 1}$ follows (28) with $S_{i}=\left(\begin{array}{ll}-w_{1} & \psi_{i}\end{array}\right)^{\prime}$,

$$
\xi_{i}=\left(\begin{array}{c}
\psi \\
-m_{1} \\
\theta \\
\lambda_{i}
\end{array}\right)
$$

and $X=\left(\begin{array}{llll}1 & 0 & 0 & 0\end{array}\right)^{\prime}$. Besides, $S_{i}$ follows (26) with

$$
H=\left(\begin{array}{ll}
1 & 1 \\
1 & 0 \\
0 & 1 \\
0 & 1
\end{array}\right)
$$


and

$$
\tilde{H}=\left(\begin{array}{ll}
1 & 1 \\
1 & 0 \\
0 & 1 \\
0 & 0
\end{array}\right)
$$

and $E\left(\xi_{i} \mid S_{i}\right)$ follows $(27)$ with

$$
P=\left(\begin{array}{cc}
k_{w}^{*} & k_{\psi}^{*} \\
1-k_{w}^{*} & -k_{\psi}^{*} \\
-\kappa k_{w}^{*} & \kappa\left(1-k_{\psi}^{*}\right) \\
-(1-\kappa) k_{w}^{*} & (1-\kappa)\left(1-k_{\psi}^{*}\right)
\end{array}\right)
$$

with $k_{w}^{*}$ and $k_{\psi}^{*}$ defined as follows:

$$
\begin{aligned}
& k_{\psi}^{*}=\frac{\left(\sigma_{\theta}^{2}+\sigma_{\lambda}^{2}\right)^{-1}}{\left(\sigma_{\psi}\right)^{-2}+\left(\sigma_{\theta}^{2}+\sigma_{\lambda}^{2}\right)^{-1}+\left(\sigma_{m}\right)^{-2}}=\frac{\sigma_{\psi}^{2}}{\sigma_{\psi}^{2}+\sigma_{\theta}^{2}+\sigma_{\lambda}^{2}+\sigma_{\psi}^{2}\left(\sigma_{\theta}^{2}+\sigma_{\lambda}^{2}\right) / \sigma_{m}^{2}} \\
& k_{w}^{*}=\frac{\left(\sigma_{m}\right)^{-2}}{\left(\sigma_{\psi}\right)^{-2}+\left(\sigma_{\theta}^{2}+\sigma_{\lambda}^{2}\right)^{-1}+\left(\sigma_{m}\right)^{-2}}=\frac{\sigma_{\psi}^{2}\left(\sigma_{\theta}^{2}+\sigma_{\lambda}^{2}\right) / \sigma_{m}^{2}}{\sigma_{\psi}^{2}+\sigma_{\theta}^{2}+\sigma_{\lambda}^{2}+\sigma_{\psi}^{2}\left(\sigma_{\theta}^{2}+\sigma_{\lambda}^{2}\right) / \sigma_{m}^{2}}
\end{aligned}
$$

and $\kappa=\sigma_{\theta}^{2} /\left(\sigma_{\theta}^{2}+\sigma_{\lambda}^{2}\right)$. Therefore, applying Lemma 3, we obtain:

$$
\left(\begin{array}{c}
K_{w}^{*} \\
K_{\psi}^{*}
\end{array}\right)=A^{\prime}=\left(\begin{array}{c}
\frac{[1+\kappa(\tilde{\sigma}-1)] k_{w}^{*}}{1+(\tilde{\sigma}-1)\left[k_{\psi}^{*}+\kappa\left(1-k_{\psi}^{*}\right)\right]} \\
\frac{\tilde{\sigma} k_{\psi}^{*}}{1+(\tilde{\sigma}-1)\left[k_{\psi}^{*}+\kappa\left(1-k_{\psi}^{*}\right)\right]}
\end{array}\right)
$$

We can write $K_{\psi}^{*}=\frac{K_{\psi}}{1+\delta / \sigma_{m}^{2}}$ and $K_{w}^{*}=\frac{\delta / \sigma_{m}^{2}}{1+\delta / \sigma_{m}^{2}}$ with $\delta=[1+\kappa(\tilde{\sigma}-1)] \sigma_{\psi}^{2}\left(\sigma_{\theta}^{2}+\right.$ $\left.\sigma_{\lambda}^{2}\right) /\left[\tilde{\sigma}\left(\sigma_{\psi}^{2}+\sigma_{\theta}^{2}\right)+\sigma_{\lambda}^{2}\right]>0$. This implies $0<K_{w}^{*}<1$ and $0<K_{\psi}^{*}<K_{\psi}<1$. Besides, $K_{\psi}<K_{\psi}^{*}+K_{w}^{*}$, since $K_{\psi}<1$.

Proof of Proposition 4.

According to Equation (10), $\hat{q}_{i 2}$ follows (28) with $S_{i}=\left(\begin{array}{llll}s^{*} & -w_{1} & -w_{2} & x_{i}^{*}\end{array}\right)^{\prime}$,

$$
\xi_{i}=\left(\begin{array}{c}
\psi \\
-m_{1} \\
-m_{2} \\
-\omega_{\theta}^{*} \theta \\
\omega_{\lambda}^{*} \lambda_{i}
\end{array}\right)
$$


and $X=\left(\begin{array}{lllll}1 & 0 & 0 & 0 & 0\end{array}\right)^{\prime}$. Besides, $S_{i}$ follows (26) with

$$
H=\left(\begin{array}{llll}
1 & 1 & 1 & 1 \\
1 & 0 & 0 & 0 \\
0 & 1 & 0 & 0 \\
0 & 0 & 1 & 0 \\
0 & 0 & 0 & 1
\end{array}\right)
$$

and

$$
\tilde{H}=\left(\begin{array}{llll}
1 & 1 & 1 & 1 \\
1 & 0 & 0 & 0 \\
0 & 1 & 0 & 0 \\
0 & 0 & 1 & 0 \\
0 & 0 & 0 & 0
\end{array}\right)
$$

and $E\left(\xi_{i} \mid S_{i}\right)$ follows (27) with

$$
P=\left(\begin{array}{cccc}
f_{s}^{*} & f_{w}^{*} & f_{w}^{*} & f_{x}^{*} \\
1-f_{s}^{*} & -f_{w}^{*} & -f_{w}^{*} & -f_{x}^{*} \\
-f_{s}^{*} & 1-f_{w}^{*} & -f_{w}^{*} & -f_{x}^{*} \\
-f_{s}^{*} & -f_{w}^{*} & 1-f_{w}^{*} & -f_{x}^{*} \\
-f_{s}^{*} & -f_{w}^{*} & -f_{w}^{*} & 1-f_{x}^{*}
\end{array}\right)
$$

with $f_{w}^{*}, f_{s}^{*}$ and $f_{x}^{*}$ defined as follows:

$$
\begin{aligned}
f_{x}^{*} & =\frac{\left(\omega_{\lambda}^{*} \sigma_{\lambda}\right)^{-2}}{\left(\sigma_{\psi}\right)^{-2}+\left(\omega_{\theta}^{*} \sigma_{\theta}\right)^{-2}+\left(\omega_{\lambda}^{*} \sigma_{\lambda}\right)^{-2}+2\left(\sigma_{m}\right)^{-2}} \\
& =\frac{\left(1+\omega_{\theta}^{*}\right)^{2} \sigma_{\psi}^{2} \sigma_{\theta}^{2}}{\left(1+\omega_{\theta}^{*}\right)^{2} \sigma_{\psi}^{2} \sigma_{\theta}^{2}+\sigma_{\psi}^{2} \sigma_{\lambda}^{2}+\left(\omega_{\theta}^{*}\right)^{2} \sigma_{\theta}^{2} \sigma_{\lambda}^{2}+2\left(\omega_{\theta}^{*}\right)^{2} \sigma_{\psi}^{2} \sigma_{\theta}^{2} \sigma_{\lambda}^{2} / \sigma_{m}^{2}} \\
f_{s}^{*} & = \\
& =\frac{\left(\omega_{\theta}^{*} \sigma_{\theta}\right)^{-2}}{\left(1+\omega_{\theta}^{*}\right)^{2} \sigma_{\psi}^{2} \sigma_{\theta}^{2}+\sigma_{\psi}^{2} \sigma_{\lambda}^{2}+\left(\omega_{\theta}^{*}\right)^{2} \sigma_{\theta}^{2} \sigma_{\lambda}^{2}+2\left(\omega_{\theta}^{*}\right)^{2} \sigma_{\psi}^{2} \sigma_{\theta}^{2} \sigma_{\lambda}^{2} / \sigma_{m}^{2}} \\
f_{w}^{*} & = \\
& =\frac{\left(\sigma_{m}\right)^{-2}+\left(\omega_{\theta}^{*} \sigma_{\theta}\right)^{-2}+\left(\omega_{\lambda}^{*} \sigma_{\lambda}\right)^{-2}+2\left(\sigma_{m}\right)^{-2}}{\left(\sigma_{\psi}\right)^{-2}+\left(\omega_{\theta}^{*} \sigma_{\theta}\right)^{-2}+\left(\omega_{\lambda}^{*} \sigma_{\lambda}\right)^{-2}+2\left(\sigma_{m}\right)^{-2}} \\
& \frac{\left(\omega_{\theta}^{*}\right)^{2} \sigma_{\psi}^{2} \sigma_{\theta}^{2} \sigma_{\lambda}^{2} / \sigma_{m}^{2}}{\left(1+\omega_{\theta}^{*}\right)^{2} \sigma_{\psi}^{2} \sigma_{\theta}^{2}+\sigma_{\psi}^{2} \sigma_{\lambda}^{2}+\left(\omega_{\theta}^{*}\right)^{2} \sigma_{\theta}^{2} \sigma_{\lambda}^{2}+2\left(\omega_{\theta}^{*}\right)^{2} \sigma_{\psi}^{2} \sigma_{\theta}^{2} \sigma_{\lambda}^{2} / \sigma_{m}^{2}}
\end{aligned}
$$

where we used the definition of $\omega_{\lambda}^{*}$. 
Therefore, applying Lemma 3, we obtain:

$$
\left(\begin{array}{c}
F_{s}^{*} \\
F_{w}^{*} \\
F_{w}^{*} \\
F_{x}^{*}
\end{array}\right)=A^{\prime}=\left(\begin{array}{l}
\frac{f_{s}^{*}}{1+(\tilde{\sigma}-1) f_{x}^{*}} \\
\frac{f_{w}^{*}}{1+(\tilde{\sigma}-1) f_{x}^{*}} \\
\frac{f_{w}^{*}}{1+(\tilde{\tilde{\sigma}}-1) f_{x}^{*}} \\
\frac{\tilde{\sigma} f_{x}^{*}}{1+(\tilde{\sigma}-1) f_{x}^{*}}
\end{array}\right)
$$

We have $0<F_{s}^{*}<1,0<F_{w}^{*}<1$ and $0<F_{x}^{*}<1$. Besides, $F_{x}^{*}+F_{s}^{*}+2 F_{w}^{*}>$ $F_{x}+F_{s}$ as shown here:

$$
\begin{array}{cccc} 
& F_{x}^{*}+F_{s}^{*}+2 F_{w}^{*} & > & F_{x}+F_{s} \\
\Leftrightarrow \quad \frac{\tilde{\sigma}\left(\omega_{\lambda}^{*} \sigma_{\lambda}\right)^{-2}+\left(\omega_{\theta}^{*} \sigma_{\theta}\right)^{-2}+2\left(\sigma_{m}\right)^{-2}}{\left(\sigma_{\psi}\right)^{-2}+\tilde{\sigma}\left(\omega_{\lambda}^{*} \sigma_{\lambda}\right)^{-2}+\left(\omega_{\theta}^{*} \sigma_{\theta}\right)^{-2}+2\left(\sigma_{m}\right)^{-2}} & > & \frac{\tilde{\sigma}\left(\omega_{\lambda} \sigma_{\lambda}\right)^{-2}+\left(\omega_{\theta} \sigma_{\theta}\right)^{-2}}{\left(\sigma_{\psi}\right)^{-2}+\tilde{\sigma}\left(\omega_{\lambda} \sigma_{\lambda}\right)^{-2}+\left(\omega_{\theta} \sigma_{\theta}\right)^{-2}} \\
\Leftrightarrow \quad \tilde{\sigma}\left(\omega_{\lambda}^{*} \sigma_{\lambda}\right)^{-2}+\left(\omega_{\theta}^{*} \sigma_{\theta}\right)^{-2}+2\left(\sigma_{m}\right)^{-2} & > & \tilde{\sigma}\left(\omega_{\lambda} \sigma_{\lambda}\right)^{-2}+\left(\omega_{\theta} \sigma_{\theta}\right)^{-2}
\end{array}
$$

This is always satisfied since $\omega_{\theta}>\omega_{\theta}^{*}$ and $\omega_{\lambda}>\omega_{\lambda}^{*}$ according to Corollary 4 . However, since $s^{*}$ and $x_{i}^{*}$ are more precise signals of $\psi$ than $s$ and $x_{i}$, as $\omega_{\theta}>\omega_{\theta}^{*}$ and $\omega_{\lambda}>\omega_{\lambda}^{*}$, but are used along with other signals, we cannot determine whether $F_{s}^{*}$ and $F_{x}^{*}$ are lower or higher than $F_{s}$ and $F_{x}$.

\section{Proof of Corollary 5.}

First, we examine the behavior of the coefficient $\omega_{\theta}^{*}$ as $\sigma_{\theta}$ goes to zero. From the definition of $K_{\psi}^{*}$ given in the proof of Proposition 3, we have:

$$
K_{\psi}^{*}=\frac{\tilde{\sigma} k_{\psi}^{*}}{1+(\tilde{\sigma}-1)\left[k_{\psi}^{*}+\kappa\left(1-k_{\psi}^{*}\right)\right]}
$$

Using the definitions of $k_{\psi}^{*}$ and $\kappa$ given in the proof of Proposition 3, we obtain that $K_{\psi}^{*}$ goes to $\tilde{\sigma} \sigma_{\psi}^{2} /\left(\sigma_{\psi}^{2}+\sigma_{\lambda}^{2}+\sigma_{\psi}^{2} \sigma_{\lambda}^{2} / \sigma_{m}^{2}\right)$. Hence, using the definition of $\omega_{\theta}^{*}$ given in Corollary 4 , we can show that $\omega_{\theta}^{*}$ goes to $(\tilde{\sigma}-1) \sigma_{\psi}^{2} /\left(\sigma_{\psi}^{2}+\sigma_{\lambda}^{2}+\sigma_{\psi}^{2} \sigma_{\lambda}^{2} / \sigma_{m}^{2}\right)$.

Using the definition of $F_{s}^{*}$ given in the proof of Proposition 4 , it is straightforward to see that $F_{s}^{*}$ goes to 1 as $\sigma_{\theta}$ goes to zero. As a consequence, $-F_{s}^{*} \omega_{\theta}^{*}$ goes to $-(\tilde{\sigma}-1) \sigma_{\psi}^{2} /\left(\sigma_{\psi}^{2}+\sigma_{\lambda}^{2}+\sigma_{\psi}^{2} \sigma_{\lambda}^{2} / \sigma_{m}^{2}\right)$.

\section{Proof of Proposition 5.}

Capital flows The household maximizes $U=U_{0}+\beta U_{1}+\beta^{2} U_{2}$, where $U_{0}, U_{1}$ and $U_{2}$ are defined as in Section 5, subject to the following intertemporal budget constraint, expressed in terms of traded goods, with the terminal condition 
$D_{2}=0$ and the initial condition $D_{-1}=0$ :

$$
\begin{aligned}
\frac{P_{0}}{P_{0}^{*}} Q_{0}+\frac{P_{1}}{r P_{1}^{*}} Q_{1}+\frac{P_{2}}{r^{2} P_{2}^{*}} Q_{2}+X_{0} & +\frac{X_{1}}{r}+\frac{X_{2}}{r^{2}}=\frac{\Pi_{0}+W_{0} L_{0}}{P_{0}^{*}}+\frac{\Pi_{1}+W_{1} L_{1}}{r P_{1}^{*}}+\frac{\Pi_{2}+W_{2} L_{2}}{r^{2} P_{2}^{*}} \\
+ & \left(1+\frac{1}{r}+\frac{1}{r^{2}}\right) \bar{X}
\end{aligned}
$$

As $r=1 / \beta$, the Euler equations for $X$ yield:

$$
\begin{aligned}
(1-\mu) e^{\theta} X_{0}^{-1} & =(1-\mu) X_{1}^{-1} \\
& =(1-\mu) X_{2}^{-1}
\end{aligned}
$$

After rearranging, we obtain:

$$
\frac{1}{e^{\theta}} X_{0}=X_{1}=X_{2}
$$

On the other hand, using the definition of profits in the non-traded sector $\Pi_{t}=P_{t} Q_{t}-W_{t} L_{t}$ and $r=1 / \beta$, we obtain the consolidated budget constraint for traded goods:

$$
X_{0}+\beta X_{1}+\beta^{2} X_{2}=\left(1+\beta+\beta^{2}\right) \bar{X}
$$

Replacing $X_{1}$ and $X_{2}$ using (31), we get the consumptions of traded goods:

$$
X_{0}=\frac{\left(1+\beta+\beta^{2}\right) \bar{X} e^{\theta}}{\beta+\beta^{2}+e^{\theta}}, \quad X_{1}=X_{2}=\frac{\left(1+\beta+\beta^{2}\right) \bar{X}}{\beta+\beta^{2}+e^{\theta}}
$$

It is then straightforward to derive the evolution of debt:

$D_{0}=X_{0}-\bar{X}=\frac{\left(\beta+\beta^{2}\right)\left(e^{\theta}-1\right)}{\beta+\beta^{2}+e^{\theta}} \bar{X}, \quad D_{1}=r D_{0}+X_{1}-\bar{X}=\beta \frac{e^{\theta}-1}{\beta+\beta^{2}+e^{\theta}} \bar{X}$

A positive aggregate transitory shock $\theta>0$ therefore generates a capital inflow in period 0 as $D_{0}>0$. In period 1 there is a capital outflow and the debt level diminishes $0<D_{1}<D_{0}$. In period 2 the household reimburses the remaining debt $\left(D_{2}=0\right)$.

Period-1 and period-2 production We proceed exactly as for Propositions 1, 2, 3 and 4. See the Technical Appendix for details. 


\section{B Numerical simulations}

\section{B.1 Monetary model with $\sigma \neq 1$}

\section{B.1.1 First period}

We denote by $\xi_{i}=\left(\begin{array}{lllll}\psi & \theta & m_{1} & m_{2} & \lambda_{i}\end{array}\right)^{\prime}$ our gaussian vector of shocks, and by $S_{i 1}=\left(\begin{array}{ll}\psi_{i} & w_{1}\end{array}\right)^{\prime}$ our vector of signals. We then define $\hat{S}_{i 1}=\left(\begin{array}{ll}\psi_{i} & \hat{w}_{1}\end{array}\right)^{\prime}$, where $\hat{w}_{1}=-\psi+m_{1}$, so that $w_{1}=\hat{w}_{1}+\frac{\sigma-1}{\sigma} \hat{q}_{1}$ and

$$
S_{i 1}=\hat{S}_{i 1}+\frac{\sigma-1}{\sigma} \hat{q}_{1}\left(\begin{array}{l}
0 \\
1
\end{array}\right)
$$

We have $\hat{S}_{i 1}=H_{1}^{\prime} \xi_{i}$ with:

$$
H_{1}=\left(\begin{array}{cc}
1 & -1 \\
1 & 0 \\
0 & 1 \\
0 & 0 \\
1 & 0
\end{array}\right)
$$

We also define:

$$
\tilde{H}_{1}=\left(\begin{array}{cc}
1 & -1 \\
1 & 0 \\
0 & 1 \\
0 & 0 \\
0 & 0
\end{array}\right)
$$

We make the following guess:

$$
\hat{q}_{i 1}=A_{1} S_{i 1}=A_{1}\left[\hat{S}_{i 1}+\frac{\sigma-1}{\sigma} \hat{q}_{1}\left(\begin{array}{l}
0 \\
1
\end{array}\right)\right]=A_{1}\left[H_{1}^{\prime} \xi_{i}+\frac{\sigma-1}{\sigma} \hat{q}_{1}\left(\begin{array}{l}
0 \\
1
\end{array}\right)\right]
$$

where $A_{1}$ is a row vector of size 2 . As a consequence:

$$
\hat{q}_{1}=A_{1}\left[\tilde{H}_{1}^{\prime} \xi_{i}+\frac{\sigma-1}{\sigma} \hat{q}_{1}\left(\begin{array}{l}
0 \\
1
\end{array}\right)\right]
$$

After rearranging, we obtain:

$$
\hat{q}_{1}=\frac{A_{1} \tilde{H}_{1}^{\prime} \xi_{i}}{1-\frac{\sigma-1}{\sigma} A_{1}\left(\begin{array}{l}
0 \\
1
\end{array}\right)}
$$


Replacing in $\hat{q}_{i 1}$, we obtain:

$$
\hat{q}_{i 1}=A_{1} M_{1}\left(A_{1}\right)^{\prime} \xi_{i}
$$

where $M_{1}\left(A_{1}\right)^{\prime}$ is a $(2,4)$ matrix such that:

$$
M_{1}\left(A_{1}\right)^{\prime}=H_{1}^{\prime}+\frac{\frac{\sigma-1}{\sigma}\left(\begin{array}{l}
0 \\
1
\end{array}\right) A_{1} \tilde{H}_{1}^{\prime}}{1-\frac{\sigma-1}{\sigma} A_{1}\left(\begin{array}{l}
0 \\
1
\end{array}\right)}
$$

We also define

$$
\tilde{M}_{1}\left(A_{1}\right)^{\prime}=\tilde{H}_{1}^{\prime}+\frac{\frac{\sigma-1}{\sigma}\left(\begin{array}{l}
0 \\
1
\end{array}\right) A_{1} \tilde{H}_{1}^{\prime}}{1-\frac{\sigma-1}{\sigma} A_{1}\left(\begin{array}{l}
0 \\
1
\end{array}\right)}
$$

Identifying, we have: $S_{i 1}=M_{1}\left(A_{1}\right)^{\prime} \xi_{i}$. Besides, we have: $E\left(\xi_{i} \mid S_{i 1}\right)=P_{1} S_{i 1}$ with

$$
P_{1}\left(A_{1}\right)=\Sigma M_{1}\left(A_{1}\right)\left[M_{1}\left(A_{1}\right)^{\prime} \Sigma M_{1}\left(A_{1}\right)\right]^{-1}
$$

where $\Sigma=\operatorname{diag}\left(\sigma_{\psi}^{2}, \sigma_{\theta}^{2}, \sigma_{m}^{2}, \sigma_{m}^{2}, \sigma_{\lambda}^{2}\right)$.

We can therefore apply Lemma 3 , and we obtain:

$$
A_{1}=\tilde{\sigma} X^{\prime} P_{1}\left(A_{1}\right)\left[I+(\tilde{\sigma}-1) \tilde{M}_{1}\left(A_{1}\right)^{\prime} P_{1}\left(A_{1}\right)\right]^{-1}
$$

When $\sigma \neq 1$, this is a nonlinear implicit equation of $A_{1}$, as $\tilde{M}_{1}$ and $P_{1}$ both depend on $A_{1}$.

To compute $A_{1}$, we implement the following algorithm:

$$
A_{1}^{t+1}=\tilde{\sigma} X^{\prime} P_{1}\left(A_{1}^{t}\right)\left[I+(\tilde{\sigma}-1) \tilde{M}_{1}\left(A_{1}^{t}\right)^{\prime} P_{1}\left(A_{1}^{t}\right)\right]^{-1}
$$

and we initialize with $A_{1}^{0}=\tilde{\sigma} X^{\prime} P_{1}^{0}\left(I+(\tilde{\sigma}-1) \tilde{M}_{1}^{0^{\prime}} P_{1}^{0}\right)^{-1}$ where $\tilde{M}_{1}^{0}=\tilde{H}_{1}$ and $P_{1}^{0}=\Sigma H_{1}\left(H_{1}^{\prime} \Sigma H_{1}\right)^{-1}$.

\section{B.1.2 Second period}

We proceed in the same way. We make the following guess:

$$
\hat{q}_{i 2}=A_{2} S_{i 2}
$$


where $S_{i 2}=\left(\begin{array}{llll}\psi_{i} & w_{1} & p_{i 1}-w_{1} & w_{2}\end{array}\right)^{\prime}$ our vector of signals. We then define $\hat{S}_{i 2}=$ $\left(\begin{array}{llll}\psi_{i} & w_{1} & p_{i 1}-w_{1} & \hat{w}_{2}\end{array}\right)^{\prime}$, where $\hat{w}_{2}=-\psi+m_{2}$, so that $w_{2}=\hat{w}_{2}+\frac{\sigma-1}{\sigma} \hat{q}_{2}$ and

$$
S_{i 2}=\hat{S}_{i 2}+\frac{\sigma-1}{\sigma} \hat{q}_{2}\left(\begin{array}{l}
0 \\
0 \\
0 \\
1
\end{array}\right)
$$

We have $\hat{S}_{i 2}=H_{2}^{\prime} \xi_{i}$ with:

$$
\left.H_{2}=\left(\begin{array}{l}
1 \\
1 \\
0 \\
0 \\
1
\end{array}\right) ; \quad\left[\left(\begin{array}{ll}
0 & 1
\end{array}\right) H_{1}^{\prime}+\frac{\sigma-1}{\sigma} A_{1} \tilde{M}_{1}^{\prime}\right]^{\prime} ; \quad\left(X^{\prime}-A_{1}\left[\tilde{M}_{1}^{\prime}+\left(M_{1}^{\prime}-\tilde{M}_{1}^{\prime}\right) / \tilde{\sigma}\right]\right)^{\prime} ; \quad\left(\begin{array}{c}
-1 \\
0 \\
0 \\
1 \\
0
\end{array}\right)\right)
$$

We also define:

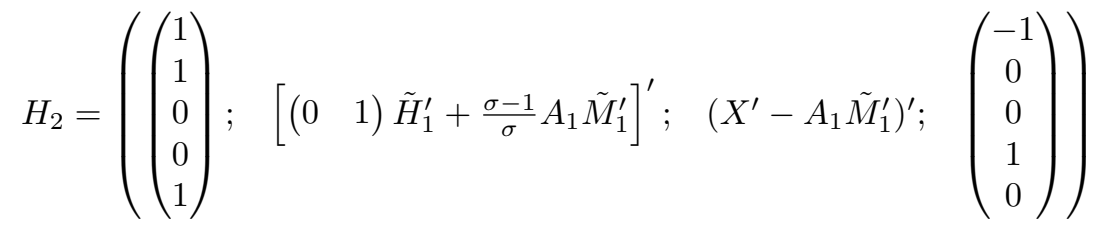

We then obtain:

$$
A_{2}=\tilde{\sigma} X^{\prime} P_{2}\left(A_{2}\right)\left[I+(\tilde{\sigma}-1) \tilde{M}_{2}\left(A_{2}\right)^{\prime} P_{2}\left(A_{2}\right)\right]^{-1}
$$

with

$$
P_{2}\left(A_{2}\right)=\Sigma M_{2}\left(A_{2}\right)\left[M_{2}\left(A_{2}\right)^{\prime} \Sigma M_{2}\left(A_{2}\right)\right]^{-1}
$$

where

$$
M_{2}\left(A_{2}\right)^{\prime}=H_{2}^{\prime}+\frac{\frac{\sigma-1}{\sigma}\left(\begin{array}{l}
0 \\
0 \\
0 \\
1
\end{array}\right) A_{2} \tilde{H}_{2}^{\prime}}{1-\frac{\sigma-1}{\sigma} A_{2}\left(\begin{array}{l}
0 \\
0 \\
0 \\
1
\end{array}\right)}
$$


and

$$
\tilde{M}_{2}\left(A_{2}\right)^{\prime}=\tilde{H}_{2}^{\prime}+\frac{\frac{\sigma-1}{\sigma}\left(\begin{array}{l}
0 \\
0 \\
0 \\
1
\end{array}\right) A_{2} \tilde{H}_{2}^{\prime}}{1-\frac{\sigma-1}{\sigma} A_{2}\left(\begin{array}{l}
0 \\
0 \\
0 \\
1
\end{array}\right)}
$$

To compute $A_{2}$, we implement the following algorithm:

$$
A_{2}^{t+1}=\tilde{\sigma} X^{\prime} P_{2}\left(A_{2}^{t}\right)\left[I+(\tilde{\sigma}-1) \tilde{M}_{2}\left(A_{2}^{t}\right)^{\prime} P_{2}\left(A_{2}^{t}\right)\right]^{-1}
$$

and we initialize with $A_{2}^{0}=\tilde{\sigma} X^{\prime} P_{2}^{0}\left(I+(\tilde{\sigma}-1) \tilde{M}_{2}^{0^{\prime}} P_{2}^{0}\right)^{-1}$ where $\tilde{M}_{2}^{0}=\tilde{H}_{2}$ and $P_{2}^{0}=\Sigma H_{2}\left(H_{2}^{\prime} \Sigma H_{2}\right)^{-1}$. 
Table 1: Baseline calibration for the numerical analysis

\begin{tabular}{|l|l|}
\hline Parameter & Value \\
\hline$\gamma$ & 1 \\
\hline$\eta$ & 0 \\
\hline $1 / \rho$ & 7 \\
\hline$\sigma_{\psi}$ & 0.1 \\
\hline$\sigma_{\theta}$ & 0.05 \\
\hline$\sigma_{\lambda}$ & 0.1 \\
\hline$\sigma_{m}$ & 0.1 \\
\hline$\sigma_{\epsilon}$ & 0.1 \\
\hline
\end{tabular}


Figure 1: Stylized facts - Profits, mark-ups and recessions

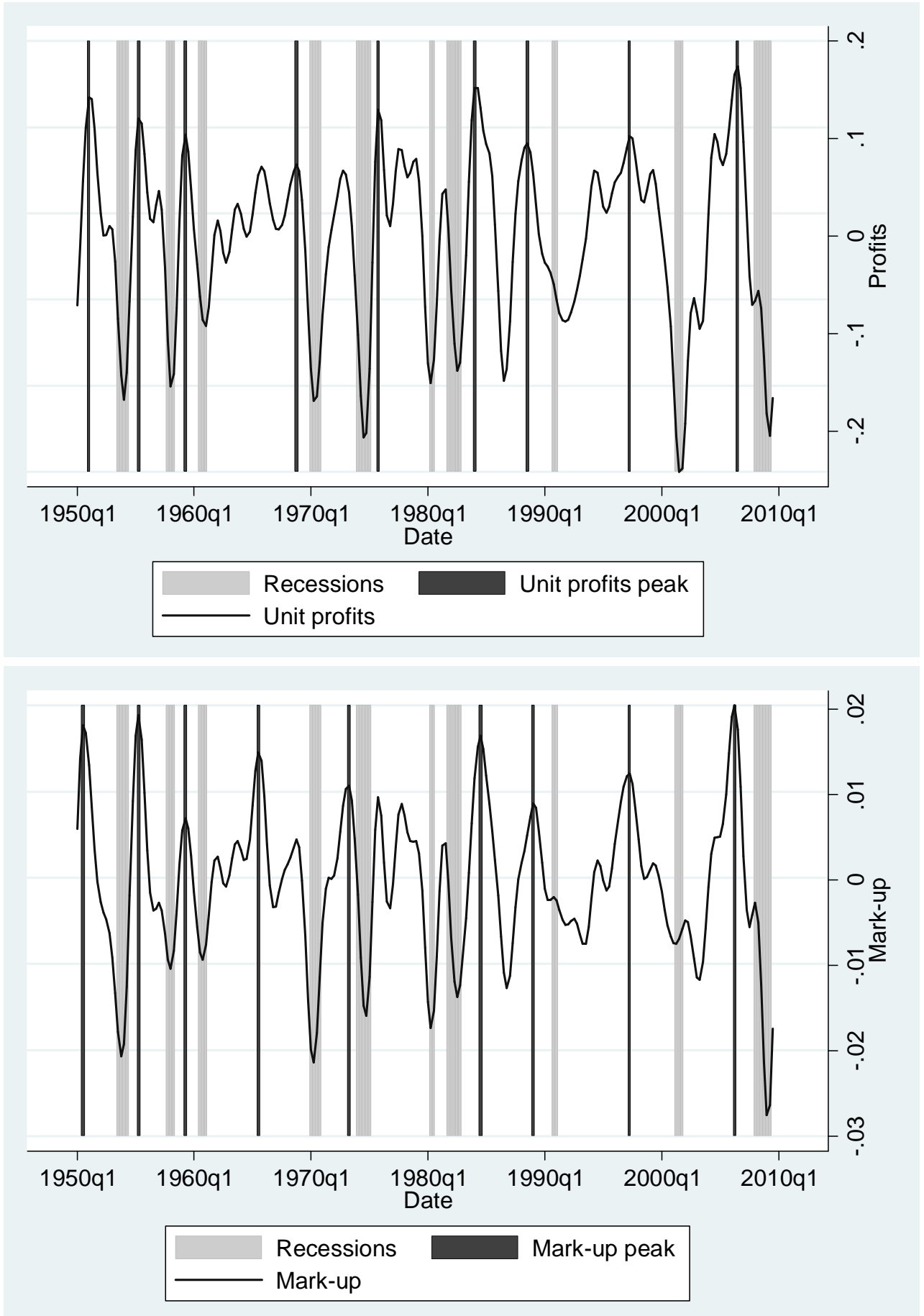

Source: NBER, Federal Reserve Bank of Saint-Louis, author's calculations. Profits are real unit profits. The mark-up is defined as labor compensation/national income. The series are detrended using the Baxter-King bypass filter. The peaks are defined the dates for which the detrended series are at a maximum over a window of $+12 / 40^{12}$ quarters. 
Figure 2: Stylized facts - Profits, expectations and GDP downturns
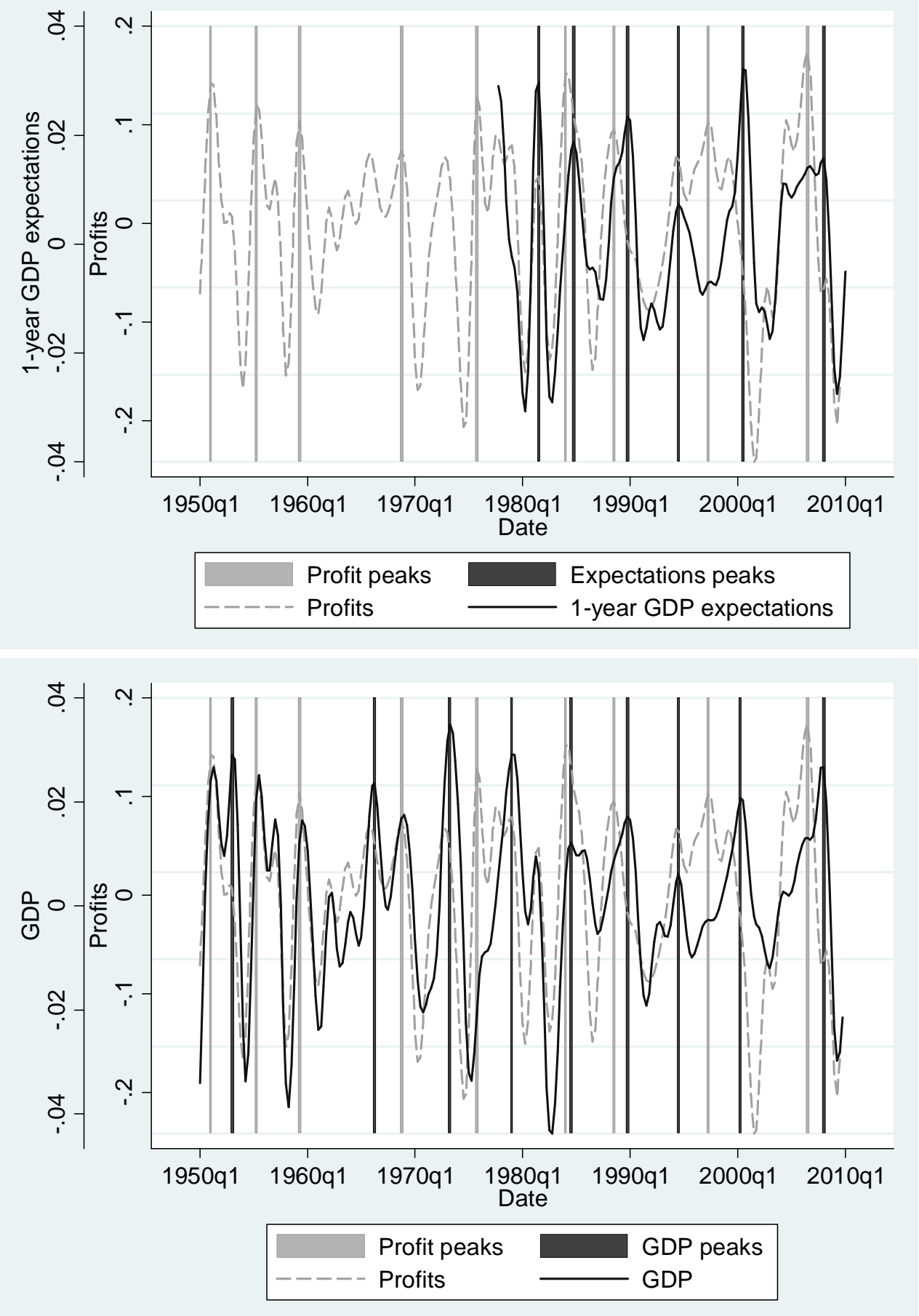

Source: Federal Reserve Bank of Saint-Louis, Federal Reserve Bank of Philadelphia (Survey of Professional Forecasters), author's calculations. The GDP and expectations series are in real terms, in logs and detrended using the Baxter-King bypass filter. The peaks are defined the dates for which the detrended series are at a 4 nnaximum over a window of $+12 /-12$ quarters. Profits are real unit profits. 
Figure 3: Impulse response functions - Simple model
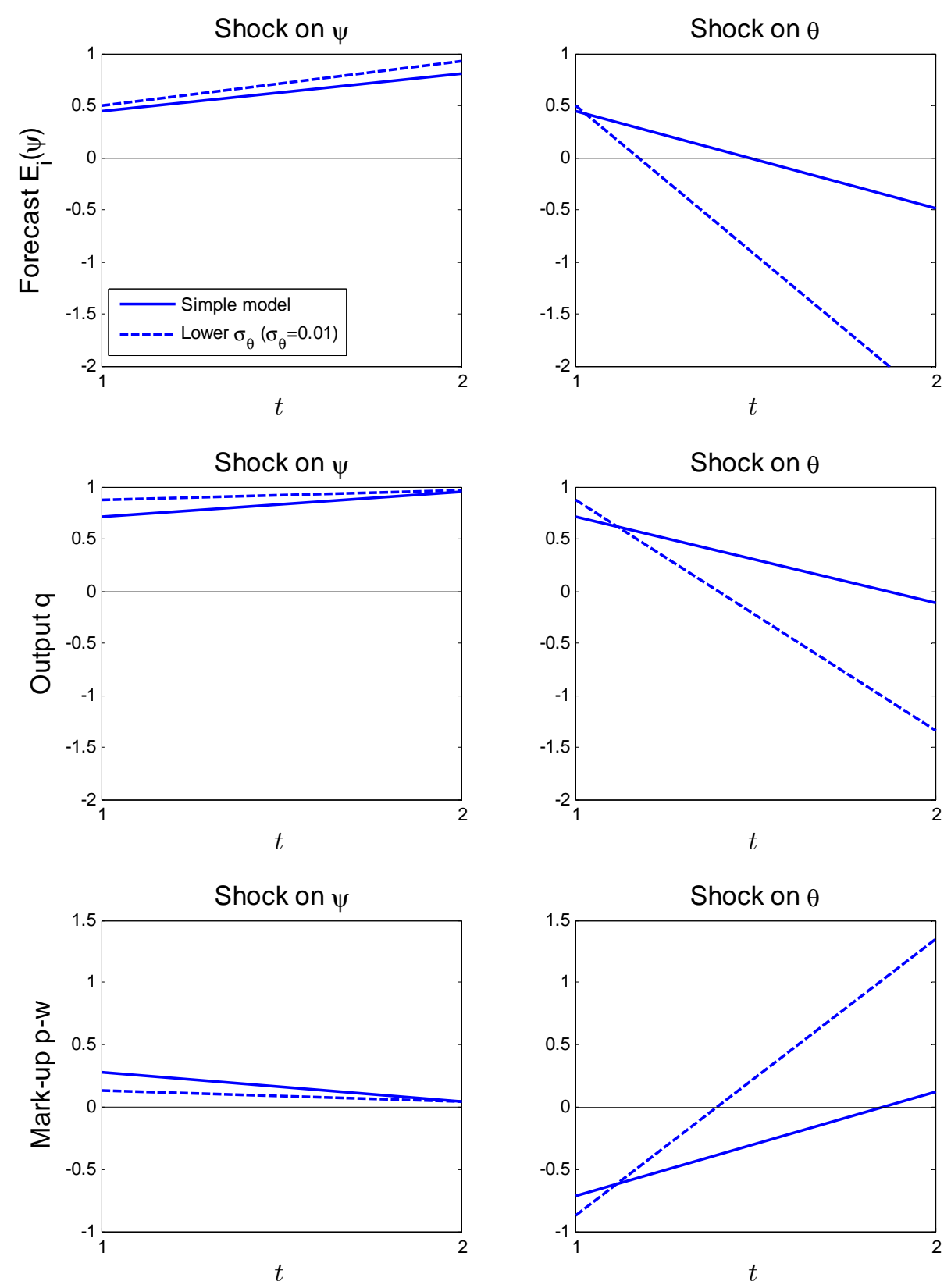


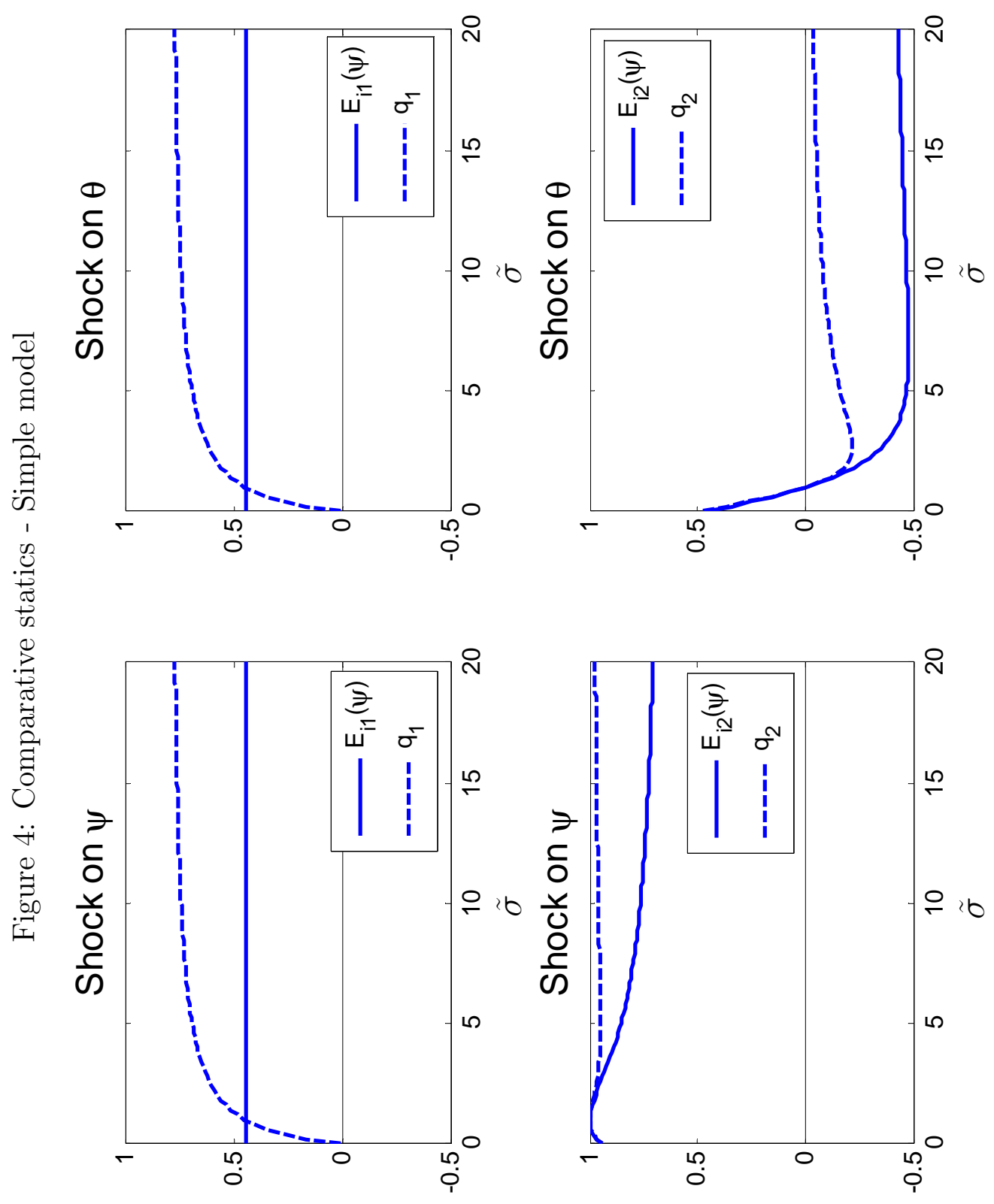


Figure 5: Impulse response functions - Monetary model
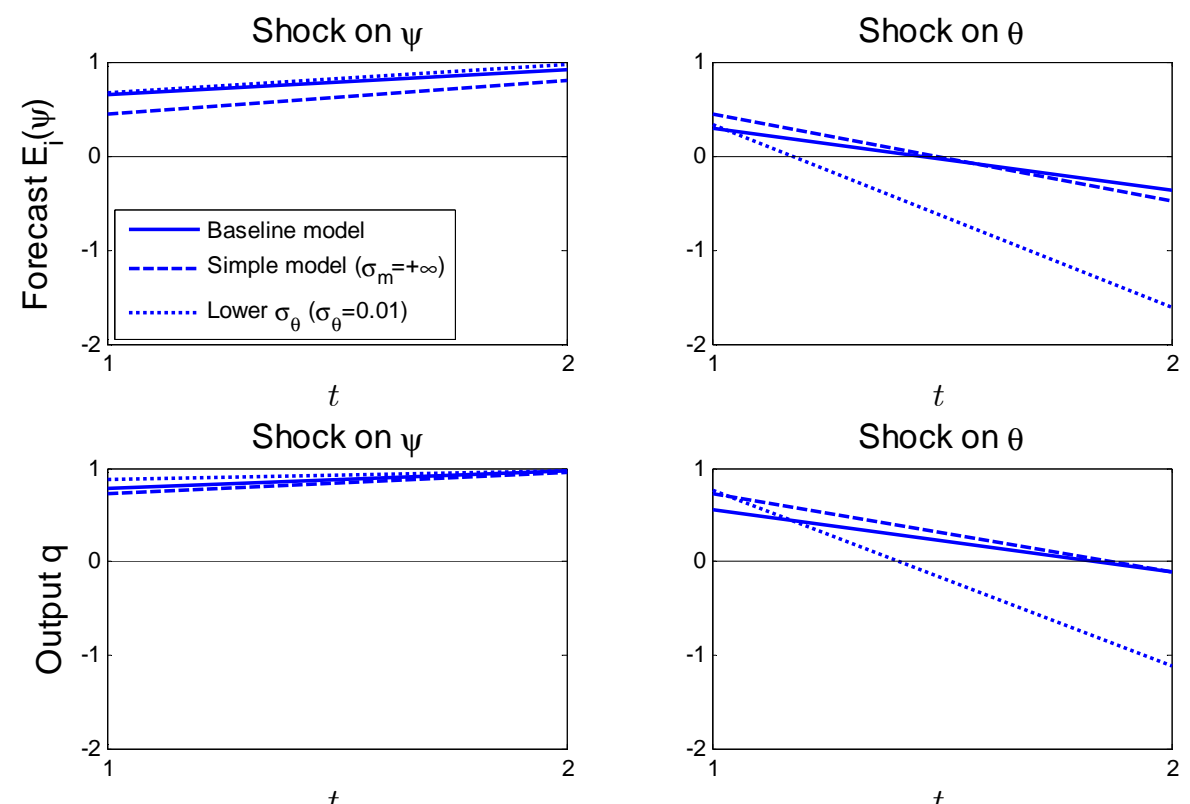

Shock on $\theta$

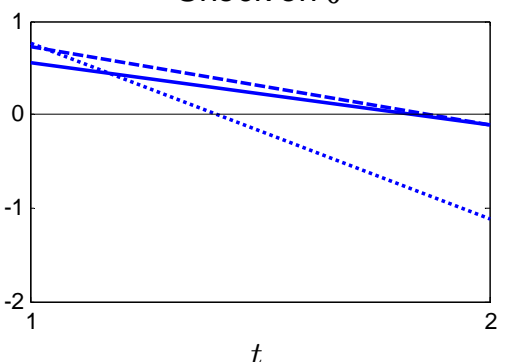

Shock on $\psi$

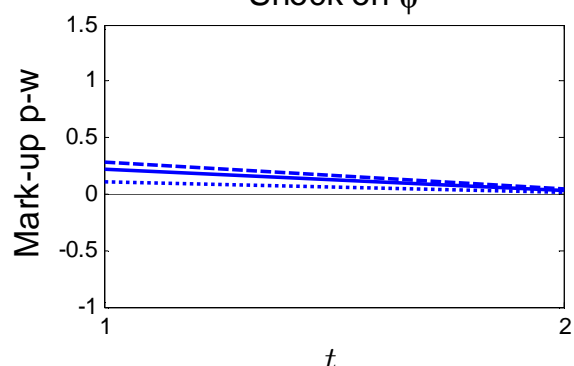

Shock on $\theta$

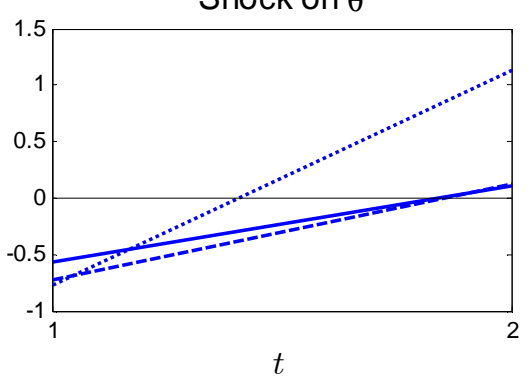

Shock on $\psi$

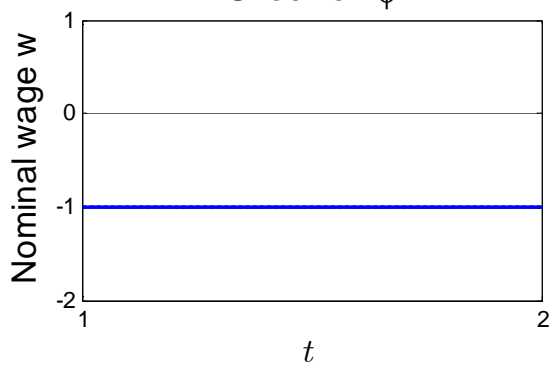

Shock on $\theta$

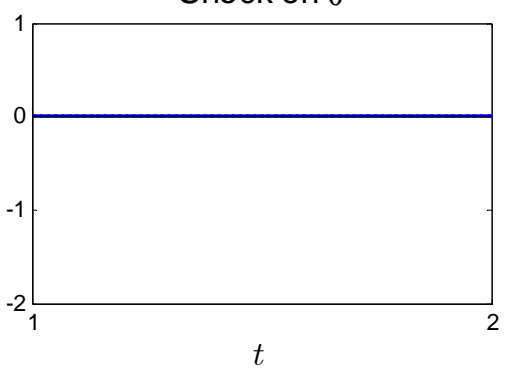


Figure 6: Impulse response functions - Monetary model - Cont'd
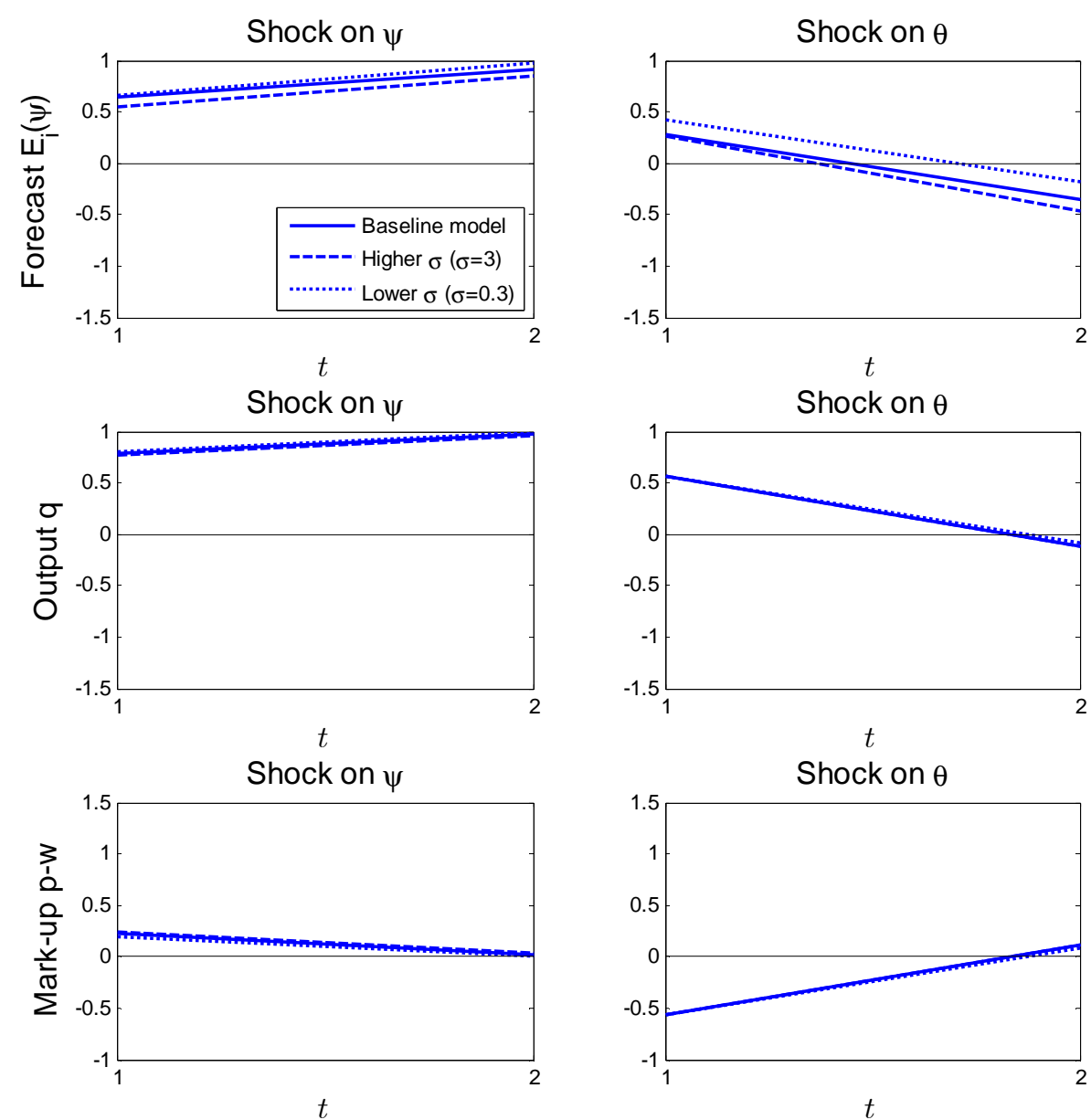

Shock on $\theta$
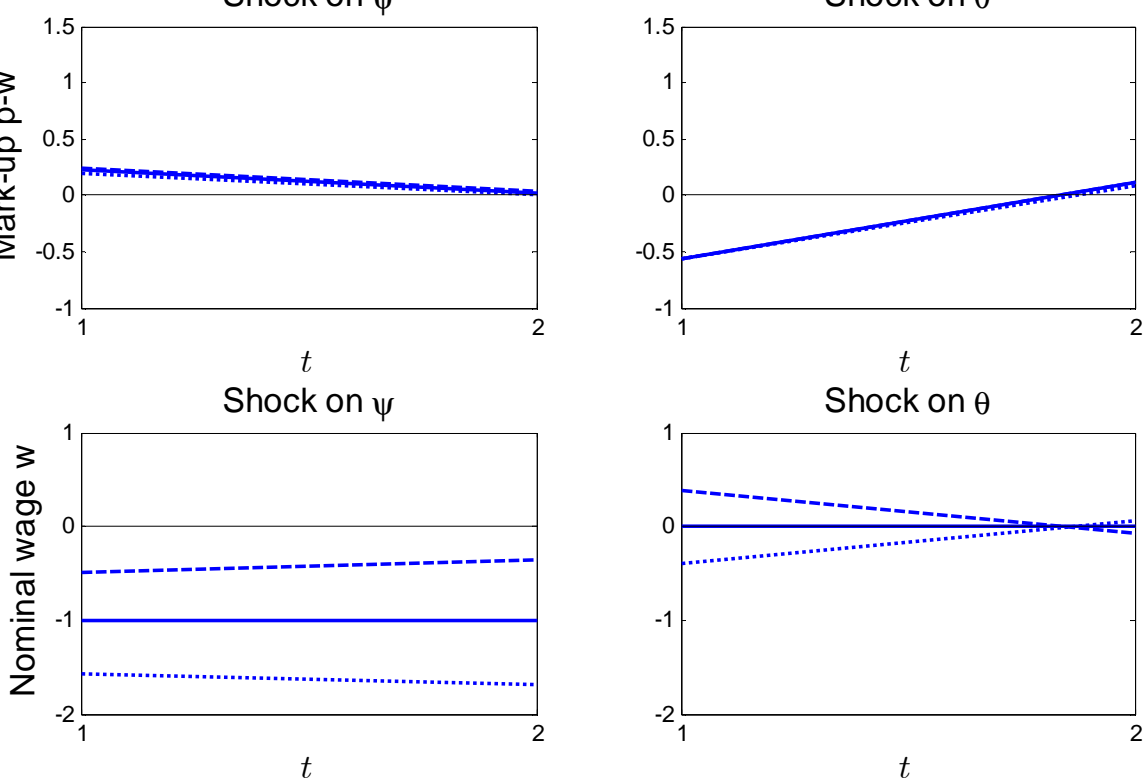